\title{
ChemComm
}

\section{Synthesis of L-hexoses and their related biomolecules}

Cite this: Chem. Commun., 2013, 49, 3275

Received 24th October 2012, Accepted 1st February 2013

DOI: $10.1039 /$ c3cc37733d

www.rsc.org/chemcomm

\author{
Medel Manuel L. Zulueta, ${ }^{a}$ Yong-Qing Zhong ${ }^{a b}$ and Shang-Cheng Hung*ac
}

Carbohydrates either conjugated or as free entities are major players in numerous biological processes. The desire to comprehend the nature of their functions and further develop therapeutic and diagnostic applications has fuelled the recent upsurge in the glycoscience field. Mainly accessed through chemical synthesis, homogeneous and well-defined sugar constructs are on high demand for structure-activity evaluation. Although the D-sugars, particularly the D-hexoses, have dominated the carbohydrate landscape, L-hexoses also attracted attention because they are known components of important polysaccharides, antibiotics, and other natural products. Nonetheless, the L-hexose-based materials needed for making building blocks for sugar assemblies are rare and are usually expensive if commercially available. Thus, intense efforts were focused on the development of innovative and reliable methods for the acquisition of L-hexoses and their derivatives. This review outlines several efficient and cost-effective routes for the chemical syntheses of L-hexoses, particularly focusing on approaches that utilize commercially abundant sugars as starting materials. A sampling of the applications of the generated L-hexoses in preparing biologically relevant compounds is also provided.
${ }^{a}$ Genomics Research Center, Academia Sinica, 128, Section 2, Academia Road, Taipei 115, Taiwan. E-mail: schung@gate.sinica.edu.tw; Fax: +886 2-2789-8771

${ }^{b}$ Department of Chemistry, National Tsing Hua University, 101, Section 2, Kuang-Fu Road, Hsinchu 300, Taiwan

${ }^{c}$ Department of Applied Chemistry, National Chiao Tung University, 1001, Ta-Hsueh Road, Hsinchu 300, Taiwan

\section{Introduction}

There is great diversity and complexity in carbohydrates-the most abundant biopolymer in Nature. ${ }^{1}$ While traditionally acknowledged as key structural supports and energy storage molecules, recent advances have also identified them as potent mediators and modulators of cellular activities. More than 50\% of proteins carry one or more sugar structures ${ }^{2}$ that, in turn, impinge on the various aspects of the protein character such as

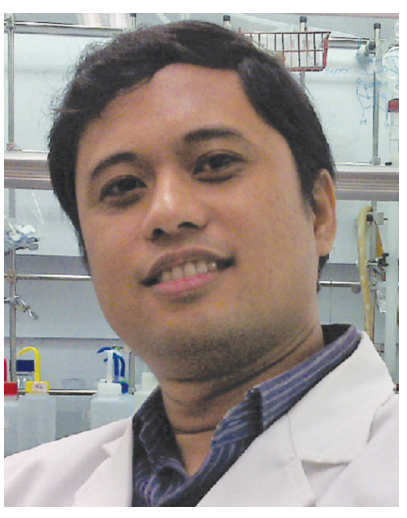

Medel Manuel L. Zulueta

Medel Manuel L. Zulueta earned his BS Chemistry degree at the Polytechnic University of the Philippines in 1997. After a few years in the private sector, he undertook graduate studies at the University of the Philippines and got the opportunity as an exchange student under Prof. Shang-Cheng Hung at the Genomics Research Center, Academia Sinica in Taiwan. He received his $P h D$ in Chemistry in 2011. He is currently working

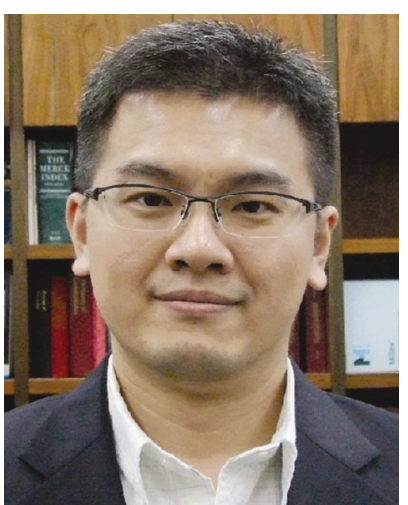

Yong-Qing Zhong
Yong-Qing Zhong was born in Taiwan and obtained his bachelor's degree in chemistry at National Central University in 2005. He is currently a PhD student at National Tsing Hua University in Taiwan under the guidance of Prof. Shang-Cheng Hung. His doctoral research is focused on the development of efficient strategies for the synthesis of heparin and heparan sulphate libraries.

with Prof. Shang-Cheng Hung in Academia Sinica as a postdoctoral fellow. His research interest is focused on the development of strategies for the chemical synthesis of oligosaccharides, particularly heparin and heparan sulphate. 
folding, targeting, trafficking, biological function, stability, and immunogenicity. ${ }^{3}$ Sugars are also found conjugated to lipids anchored at plasma membranes ${ }^{4}$ and as components of several natural products profoundly contributing to potency. ${ }^{5}$ Cellsurface carbohydrates have pivotal roles in recognition, adhesion, and signalling that affect numerous biological processes from fertilization to development and from bacterial and viral infections to immune response. Such plethora of functions emerges from the exquisite structural complexity that these materials are able to exploit. ${ }^{6}$ Individual sugar units are polyhydroxylated and bear multiple chiral centres. Numerous positions in their furanosidic or pyranosidic rings are amenable to linkage with another unit to form polymers that may be linear or branched. As a result, carbohydrate polymers hold extensive structural information density, beating nucleic acids and proteins by a long shot. Altogether, these findings fuelled the growth of glycobiology as they seek to unravel the intricacies of sugar functions and further provide inspirations for the development of novel diagnostic and pharmaceutical agents. ${ }^{7}$

Natural sugar constructs are generated using a non-templatedriven process and are often heterogeneous, complicating isolation and purification. ${ }^{6}$ Thus, chemical synthesis remains the most common source of pure well-defined carbohydrate structures for evaluating structure-activity relationships. ${ }^{8}$ The relative ease of preparation of these compounds is dependent, in part, on the ready access to monosaccharide building blocks in the form of glycosyl donors and acceptors. Present in most oligo- and polysaccharides, D-sugars, particularly D-hexoses, are widely accessible. As for the L-form sugar units, only L-arabinose, L-fucose (6-deoxy-L-galactose), and L-rhamnose (6-deoxy-L-mannose) can be obtained in ample quantities from natural sources. The prevalence of these monosaccharides gave way to the straightforward preparation of corresponding building blocks for oligosaccharide assembly. In addition to their applications in sugar synthesis, they have been conveniently explored as chiral sources and as asymmetric catalysts in organic reactions. ${ }^{9}$

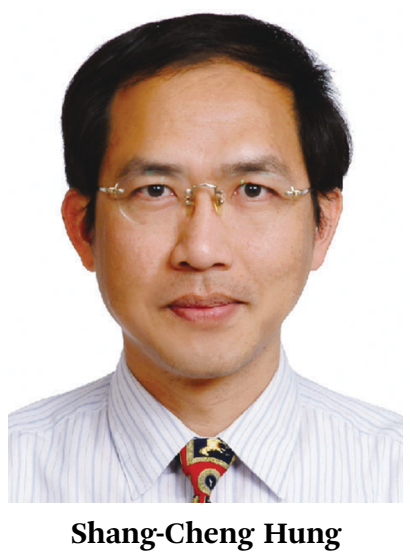

Shang-Cheng Hung obtained his PhD from National Tsing Hua University of Taiwan in 1992. After postdoctoral research with Prof. Andrew Streitwieser at University of California, Berkeley, and Prof. Chi-Huey Wong at Scripps Research Institute, he started his independent research at the Institute of Chemistry, Academia Sinica in 1998. In 2005, he moved to the Department of Chemistry, National Tsing Hua University. He is currently a Distinguished Research Fellow at the Genomics Research Center, Academia Sinica. His research focuses on carbohydrate chemistry and chemical biology, including the synthesis of heparin oligosaccharides and mycobacterial cell envelope components together with their bioevaluation.
L-Hexoses have also attracted significant attention despite their limited natural occurrence. Numerous biologically potent compounds contain L-hexoses within their structure (Fig. 1). For instance, the repeating disaccharide units (1 and 2) of heparin, heparan sulphate, and dermatan sulphate glycosaminoglycans include L-iduronic acid. ${ }^{10}$ These polyanionic polysaccharides act as binding sites for various proteins, dynamically affecting the biological activity of the ligand. Here, L-iduronic acid, which assumes several conformations in solution, provides added flexibility to the polymer and, thus, is commonly situated at protein binding sites. Alginates (3), the polysaccharide from brown algae and some bacterial species, include blocks of D-mannuronic acids and L-guluronic acids as well as regions with mixed units. ${ }^{11}$ High levels of L-guluronic acid within the polymer confer increased selective binding capability to metal ions affecting gel formation, stability, and immunogenicity. L-Altruronic acid, on the other hand, is a key feature in the tetrasaccharide repeating units of the Proteus mirabilis $\mathrm{O} 10(\mathbf{4})^{\mathbf{1 2}}$ and Aerococcus viridans var. homari ${ }^{13}$ capsular polysaccharides. Moreover, the extracellular polysaccharides of Butyrivibrio fibrisolvens strain CF3 carry L-altrose as a typical component. ${ }^{14}$ Meanwhile, L-galactose occurs in the A side chain of the pectic polysaccharide rhamnogalactorunan II (5). ${ }^{15}$ L-Mannose together with L-rhamnose are structural components of the related capsular polysaccharides S-88 (6), S-130, and S-198 from Sphingomonas, which possess diverse industrial and food applications. ${ }^{16}$ The carbohydrate component of the potent antitumour antibiotic bleomycin $\mathrm{A}_{2}$ (7) comprises D-mannose $\alpha 1 \rightarrow 2$-linked to L-gulose. ${ }^{17}$ This moiety plays a crucial role in cell-surface recognition and is associated with the metal-binding domain of the molecule. Conversely, the antibiotics neomycin B (8), ${ }^{18}$ adenomycin, ${ }^{19}$ and capuramycin, ${ }^{20}$ possess the sugars 2,6-diamino-2,6-dideoxyL-idose, L-gulosamine, and 3-O-methyl-L-talofuranosyluronamide, respectively. Apoptolidin A (9), a macrolide with attached 6-deoxy-L-glucose from Nocardiopsis species, is a selective inducer of apoptosis in tumour cells. ${ }^{21}$ The sulphated glycopeptidolipid from the Mycobacterium avium cell wall (10) has a 6-deoxy-L-talose residue. ${ }^{22}$ Some terpenoids were also found conjugated to L-sugars such as L-idose from Aster spathulifolius Maxim (11) ${ }^{23}$ and L-galactose from the marine octocoral Muricea $c f$. purpurea. ${ }^{24}$ Natural compounds aside, the evident absence of chiral specificity in mammalian taste buds allowed L-sugars such as L-glucose and L-fructose to be explored as potential noncaloric sweeteners. ${ }^{25}$ Their use, however, was primarily curtailed by the cost of preparation of these simple compounds. Phenolic conjugates of L-iduronic acid and L-mannose are utilized as substrates for measuring the activity of L-iduronidase ${ }^{26}$ and the commercial naringinase, ${ }^{27}$ respectively. Carbohydrate constructs that are mirror images of natural D-sugar-dominated structures are also being explored to further understand the interactions with protein and other biomolecules including their potential in evading antibody detection and enzyme degradation. ${ }^{28}$

With the need becoming more evident, particularly as building blocks in oligosaccharide assembly, various synthetic approaches were conceived to gain access to the rare L-hexoses. ${ }^{29}$ The novel strategies advanced by several groups include de novo 


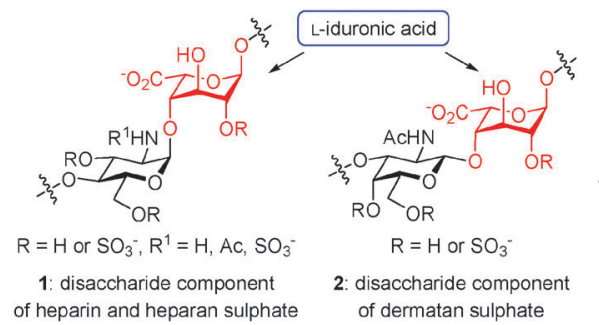

of heparin and heparan sulphate
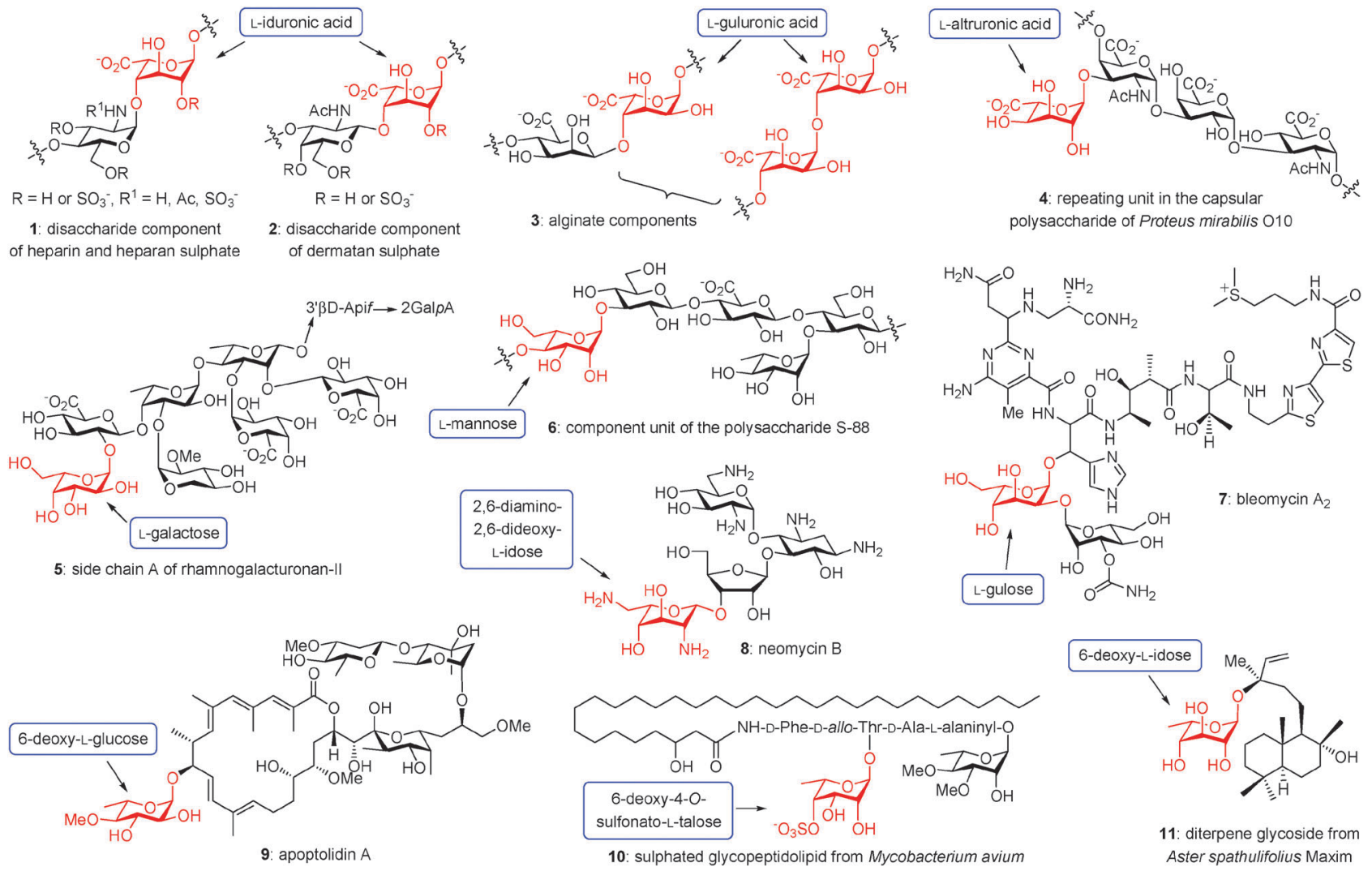

Fig. 1 Some natural compounds that have L-hexoses in their structures.

syntheses from non-sugar starting materials, ${ }^{30-33}$ multicarbon elongation of shorter monosaccharides, ${ }^{34}$ elaboration of the more abundant $\mathrm{D}^{-}$and L-sugar forms, and enzymatic synthesis. ${ }^{35}$ As the topic became the subject of numerous intense investigations, we focused this review on the preparation of L-hexoses using the abundant pentoses and hexoses as starting materials. In such cases, the synthetic routes are relatively simple, convenient, and cost effective, enabling large scale preparations to be carried out. Because most chiral centres in the starting materials are already in place, these routes are largely straightforward and, although they still pose some concerns and an area for improvement, issues on reaction stereoselectivity are minimal. Many of the $\mathrm{L}$-form products are also judiciously decorated with protecting groups suitable for their target application. Finally, we also present some synthetic examples that utilize L-hexose building blocks in the assembly and total synthesis of biologically relevant compounds.

\section{Epimerisations}

Hexoses mainly differ in the stereochemistry of one or more hydroxyl (or amine) groups. Epimerisation can, therefore, be devised to access many rare L-hexoses from their readily available D- and L-configured counterparts. This convenient and practical route has been extensively applied, with several distinct strategies available.

The orientation of the oxygen substituent at the C-5 position is what separates the realms of $\mathrm{D}^{-}$and L-hexoses. Plain D-hexoses have an $R$-configured C-5, whereas, in L-hexoses, C-5 is $S$-configured.
Consequently, a C-5 inversion would convert the very abundant D-glucose into the rare L-idose and for that matter, D-mannose into L-gulose and D-galactose into L-altrose. The preparations of L-idose and L-iduronic acid building blocks, often demanded by the synthesis of chemically pure glycosaminoglycan analogues, ${ }^{36}$ were mostly carried out in this manner. A representative sampling of the strategies involving the C-5 epimerisation of D-gluco compounds towards the L-ido configuration is shown in Scheme 1. The $\mathrm{S}_{\mathrm{N}} 2$ substitution of the 5-triflate derivative of the uronate 12 generated the L-ido isomer. Cleavage of the levulinate (Lev) ester furnished the alcohol 14 and, by further acid hydrolysis of the isopropylidene protection, provided the triol 15. ${ }^{37}$ As often is the case with an unprotected 5-hydroxyl, freeing the anomeric position of the generated L-hexofuranoside leads to the formation of a mixture of furanosyl and pyranosyl products that have to be dealt with to avoid complications in the succeeding steps. Consequently, some groups implemented the epimerisation of the C-5 stereocentre without opening the pyranose ring of the D-sugar. Wong and co-workers performed free radical bromination at the C-5 position of the pyranose 16 using $N$-bromosuccinimide (NBS) in refluxing $\mathrm{CCl}_{4}$ under UV light. ${ }^{38}$ A dibutyltin hydride-mediated reduction at C-5 delivered the L-iduronate $\mathbf{1 8}$ as the major product, of which the orientation of the anomeric acetate displayed an influence on yield. Compound 19, on the other hand, was first converted into the 6-iodide $\mathbf{2 0}$ and, then, into the exo-glycal by elimination of $\mathrm{HI}$ through the assistance of 1,8-diazabicyclo[5.4.0] undec-7-ene (DBU). ${ }^{39}$ Hydroboration of 22 with 9-borabicyclo[3.3.1] nonane (9-BBN) produced the L-idose 

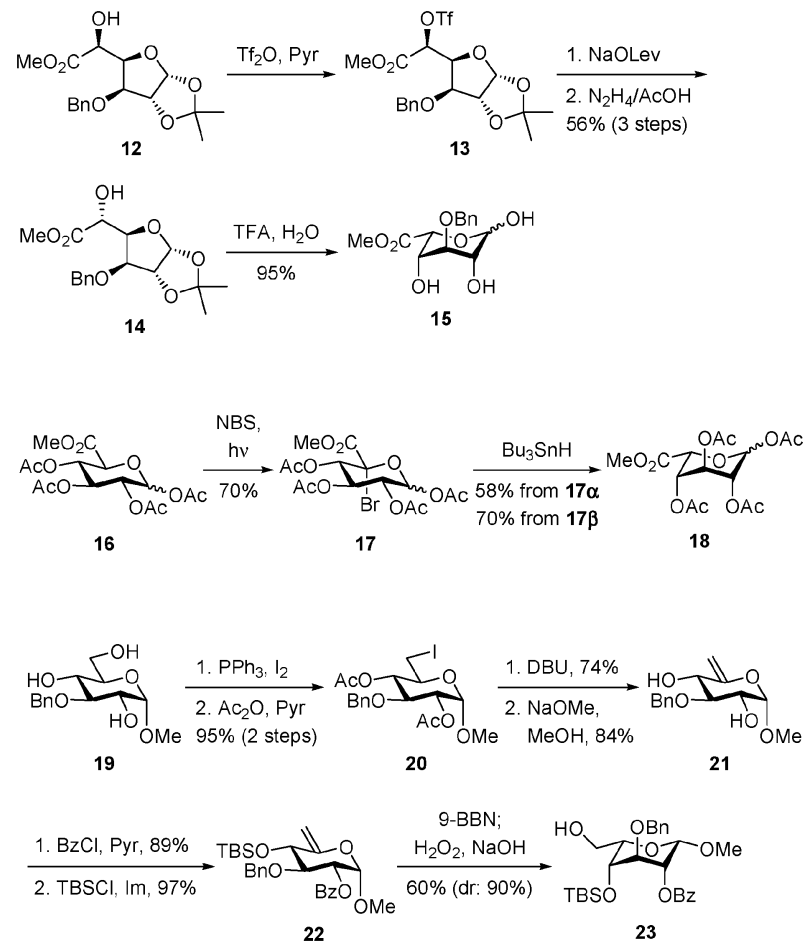

Scheme 1 Examples of procedures in transforming D-g/uco into the L-ido configuration.

derivative 23 in $60 \%$ yield and $90 \%$ facial selectivity. Replacement of the tert-butyldimethyl silyl (TBS) and benzoyl groups reduced the diastereoselectivity of the addition process.

The preparation of the L-gulose derivative by Kobayashi et $a l^{40}$ through epimerisation at the $\mathrm{C}-5$ position of D-mannose is illustrated in Scheme 2. Phosphonium ylide treatment of the hemiacetal 24 led to the hydroxyolefin 25. Swern oxidation of this 5 -alcohol formed the dioxanone, which was stereoselectively reduced by L-selectride to afford the L-gulo compound 26 in $83 \%$
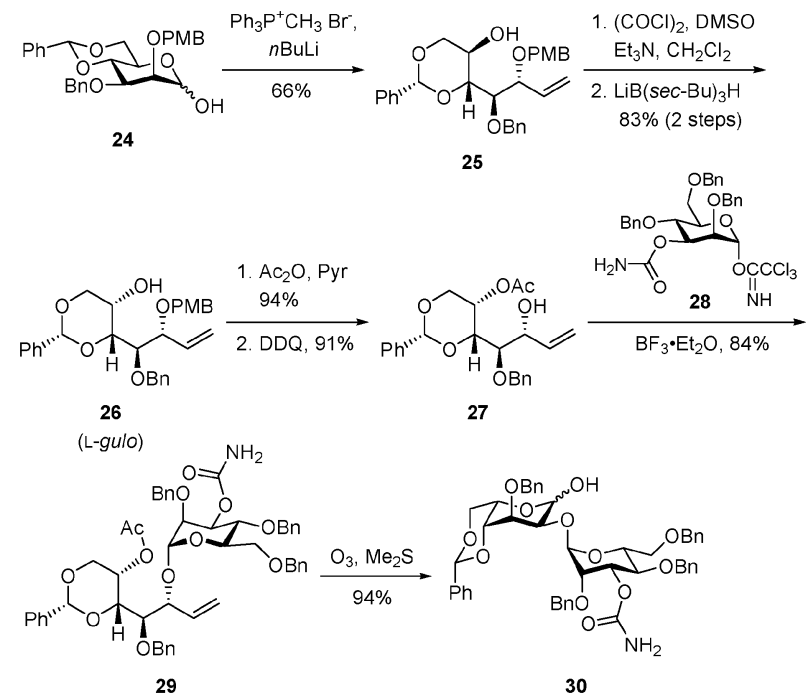

Scheme 2 Epimerisation of D-mannose into L-gulose and the preparation of the disaccharide moiety of bleomycin.
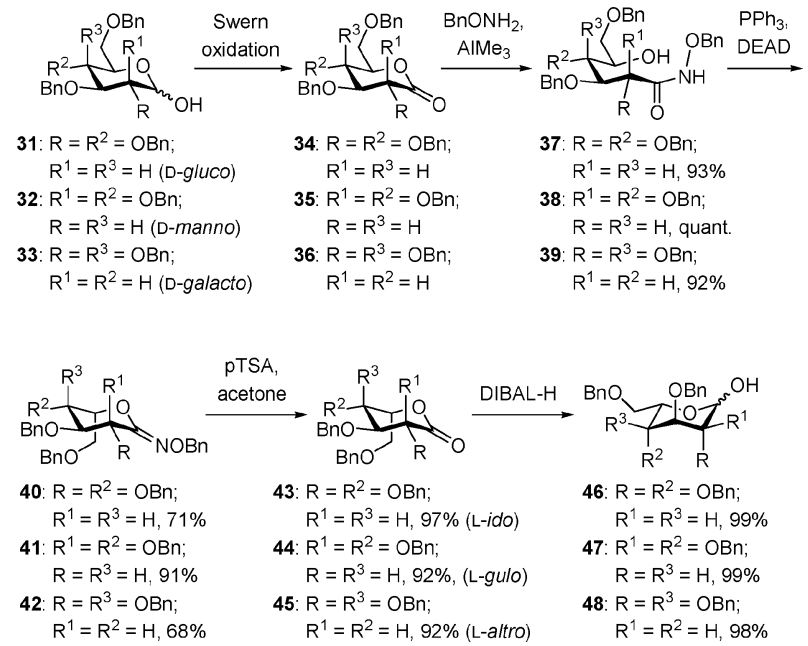

Scheme 3 C-5 epimerisation through $\delta$-hydroxybenzyloxamate.

yield over two steps as a single isomer. Further acetylation, p-methoxybenzyl (PMB) deprotection using 2,3-dichloro-5,6dicyano-1,4-benzoquinone (DDQ), and subsequent glycosylation with the mannosyl donor 28 supplied the adduct 29. Upon ozonolysis, the disaccharide 30, which carries the backbone of the bleomycin carbohydrate moiety, was obtained.

Ikegami's group carried out the epimerisation at C-5 of D-glucose, D-mannose, and D-galactose via $\delta$-hydroxyalkoxamine (Scheme 3). ${ }^{41}$ The D-glyconolactones 34-36, obtained from the hemiacetals 31-33, were exposed to $O$-benzylhydroxylamine and $\mathrm{AlMe}_{3}$ to form the desired benzyloxamines 37-39 in excellent yield. In the presence of $\mathrm{PPh}_{3}$ and diethylazodicarboxylate (DEAD) in THF, O-cyclisation appeared more favoured than the competing $N$-cyclisation with elimination of triphenylphosphine oxide and epimerisation at C-5. The so-formed oximes 40-42 were, then, transformed to the corresponding L-glyconolactones 43-45 upon acid hydrolysis. Reduction with diisobutylaluminium hydride (DIBAL-H) provided the hemiacetals having the L-ido (46), L-gulo (47), and L-altro (48) configurations. Different alkoxamines, protecting groups, and reaction solvent influence the $\mathrm{N}$-/O-cyclisation ratio. Thus, by a judicious selection of parameters, L-iminosugars can also be effectively prepared using this route.

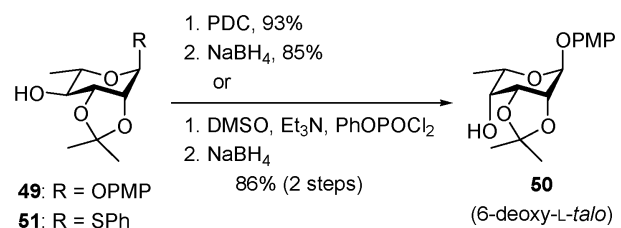

51: $R=S P h$

$$
\begin{array}{|l}
\text { 1. Mel, } \mathrm{KOH}, 99 \% \\
\text { 2. pTSA, } 89 \% \\
\text { 3. TBSCI, Im, } 91 \%
\end{array}
$$

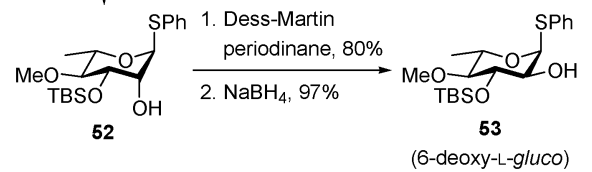

Scheme 4 Preparation of the 6-deoxy-L-hexose from L-rhamnose. 

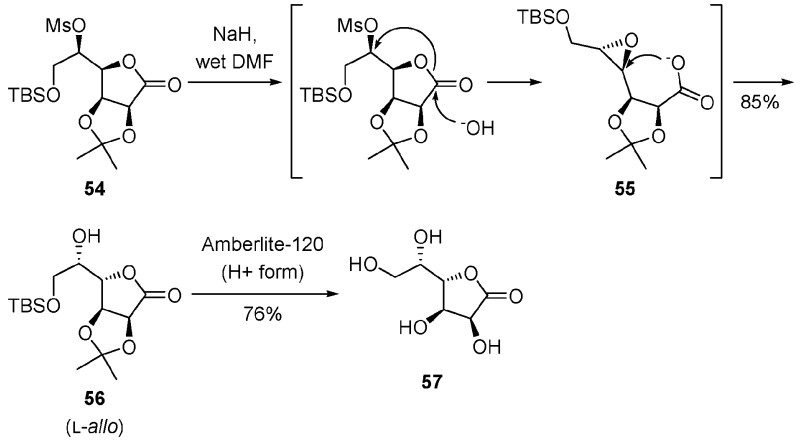

Scheme 5 Double inversion in D-mannose.

The relative availability of L-rhamnose makes it a suitable starting material to access some important 6-deoxy-L-hexoses through plain epimerisation. For example, 6-deoxy-L-talose building blocks required for the synthesis of several natural products were readily prepared from L-rhamnose (Scheme 4). In the synthesis carried out by Zhang's group, ${ }^{42}$ the 1,2 -isopropylidene-protected $p$-methoxyphenyl (PMP) rhamnoside (49) was subjected to pyridinium dichromate (PDC) or Pfitzner-Moffatt oxidation at C-3 to form the ketone, which was treated with $\mathrm{NaBH}_{4}$ to acquire the desired 6-deoxy-L-talose derivative $\mathbf{5 0}$. Conversely, the 6-deoxy-L-glucose donor used for the total synthesis of apoptolidin A and its analogues was prepared by Koert et al. from L-rhamnose. ${ }^{43}$ Here, the properly protected 2-alcohol 52 was first prepared from the thiorhamnoside 51. To secure the desired L-gluco-configured 53, C-2 was oxidised with Dess-Martin periodinane followed by hydride addition. In both of these cases, the highly stereoselective reduction steps were likely influenced by steric factors.

Shih and Tseng were able to perform two-fold inversions at the adjacent C-4 and C-5 stereocentres in a D-mannose backbone, leading towards the L-allose derivative (Scheme 5). ${ }^{44}$ The D-mannonolactone 54, readily attainable from D-mannose, was treated with sodium hydride in a 4:1 DMF-water mixed solvent. The hydroxide ion generated in situ was presumed to bring about the $\mathrm{S}_{\mathrm{N}} 2$ displacement of the mesylate group at C-5 by the so-formed oxide at C-4, generating the epoxide 55. A second displacement at C-4 by the resultant carboxylate furnished compound 56 with an L-allo backbone. 1,4-L-Allonolactone (57) was afforded after acid exposure of $\mathbf{5 6}$.

Our efforts in attaining various L-hexoses relied on multiple epimerisations starting from the commercially abundant diacetone D-glucose (58), with the first epimerisation carried out at C-5 to form the L-ido derivative (Scheme 6). ${ }^{45}$ Treatment of 58 with $\mathrm{PPh}_{3}$ and NBS enabled the formation of the 6-bromide $\mathbf{6 1}$ possessing 1,2;3,5-di-O-isopropylidene groups locked in a cis-anti-cis fused tricyclic core. Here, the 3-oxyphophonium intermediate 59 likely forms first, but the acetonide transfer from the 5,6- to 3,5-position apparently occurs faster than the $\mathrm{S}_{\mathrm{N}} 2$ displacement by the bromide ion. The alternative and less sterically hindered substitution at the C-6 position of $\mathbf{6 0}$ is, hence, more favoured as evidenced by the isolation of compound $\mathbf{6 1}$ in $75 \%$ yield. Facile dehydrobromination by DBU delivered the enol ether 62. Both agents in the palladium-catalysed hydrogenation and hydroboration attacked
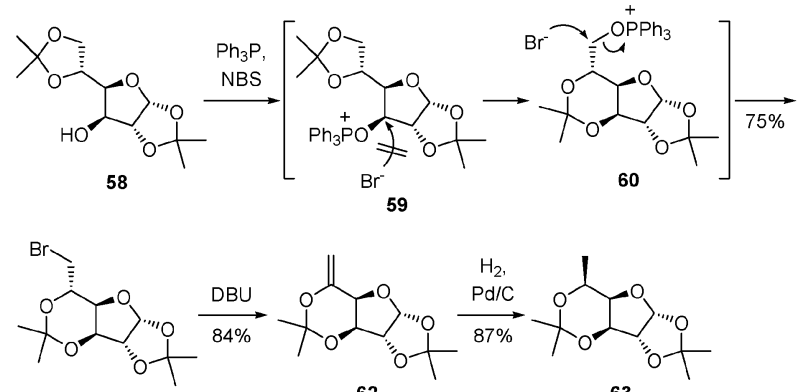

61

62

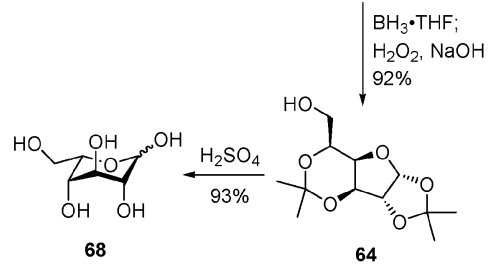

L-idose

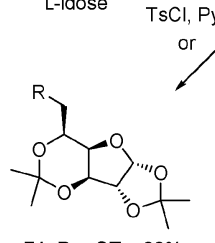

71: $\mathrm{R}=$ OTs, $88 \%$

72: $R=F, 55 \%$
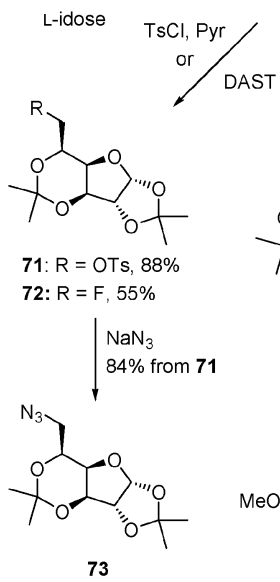

64

(L-ido)

\begin{tabular}{l|l} 
1. TEMPO, $\mathrm{NaOCl}$ \\
2. Mel, $\mathrm{KHCO}_{3}$
\end{tabular}

$88 \%$ (2 steps)

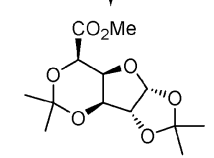

69

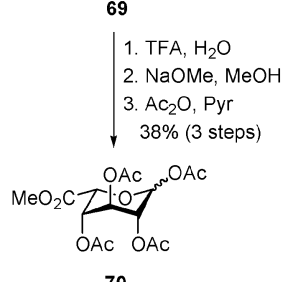

(6-deoxy-L-ido)

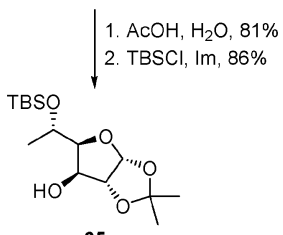

65

1. $\mathrm{PDC}, \mathrm{Ac}_{2} \mathrm{O}$

2. $\mathrm{NaBH}_{4}$

$82 \%$ (2 steps)

TBSO

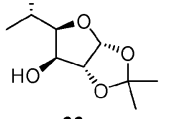

66

(6-deoxy-L-talo)

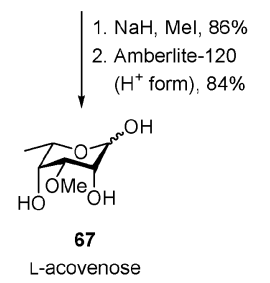

Scheme 6 Entry to the L-hexoses from D-glucose.

stereoselectively the less congested $R e$-face of the compound $\mathbf{6 2}$ alkene function to furnish the respective L-ido products 63 and 64. It should be mentioned that the same transformations and selectivity has been observed when a benzylidene acetal protects the 3,5-O position instead of isopropylidene. ${ }^{45 d, e, 46}$ Following the regioselective 3,5-O-isopropylidene ring cleavage and 5-O-silylation of 63, a next round of epimerisation, this time at the 3-O position of the 6-deoxy-L-ido compound, was carried out. Consequently, $\mathrm{PDC}$ oxidation and, then, $\mathrm{NaBH}_{4}$ reduction provided the desired 6-deoxy-L-talo compound 66 in high yield. The sugar L-acovenose (67) was obtained after 3-O-methylation and acidic deprotection. L-Idose (68) was accessed from compound 64 after a simple acid hydrolysis. Moreover, further functionalization at C-6 of 64 can be readily carried out. For instance, 2,2,6,6tetramethyl-1-piperidinyloxyl (TEMPO) free radical oxidation allowed the acquisition of L-iduronate 69 following methyl ester formation. This compound can be re-protected in 3 steps to get the tetraacetate 70. The free 6-hydroxyl group also permits replacement with other functionalities such as fluoride (compound 72) or azide (compound 73).

To enable the epimerisation at other positions of the L-idose derivative 64, regioselective hydrolysis and 5,6-O-isopropylidenation were implemented, generating the 3-alcohol 74 (Scheme 7). 


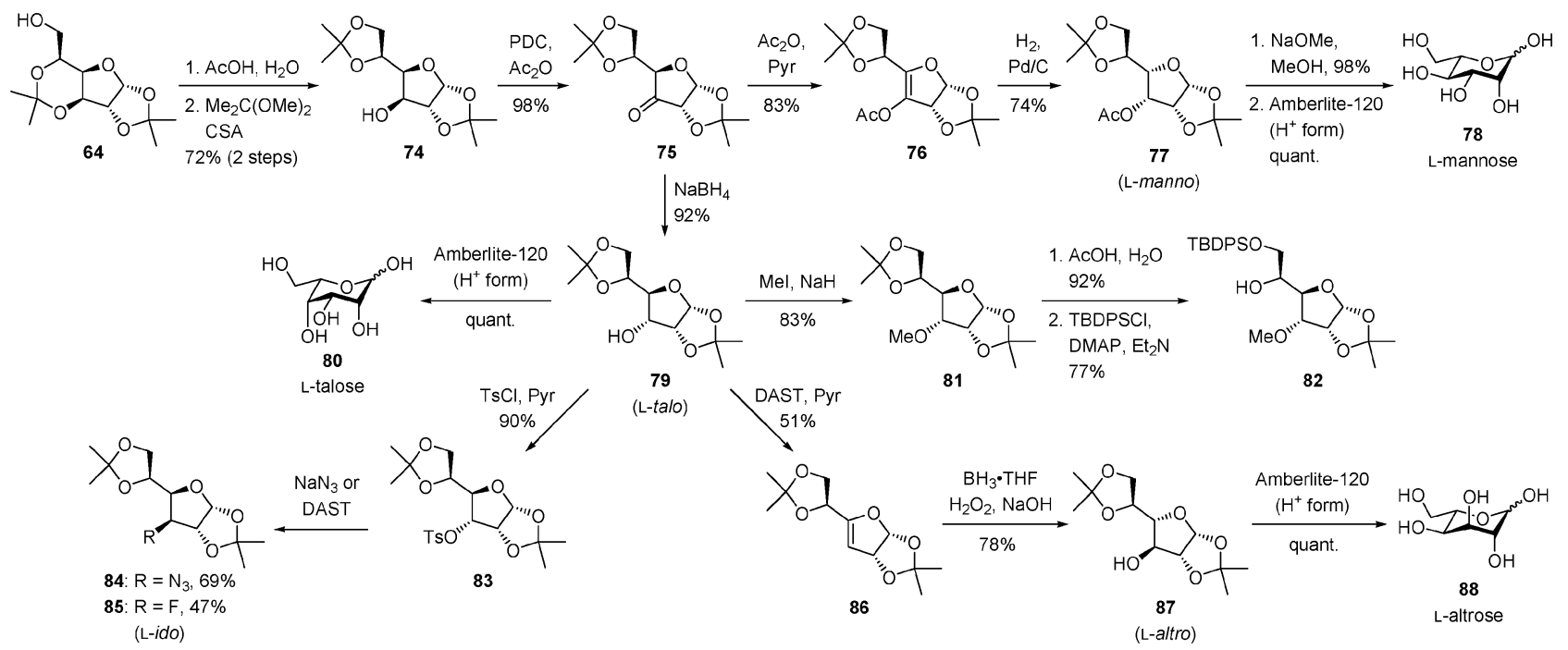

Scheme 7 Preparation of various L-hexoses from L-idose.

To get L-mannose from L-idose, inversions of stereochemistry at C-3 and C-4 positions are needed. Accordingly, 74 was oxidised by PDC to procure the ketone $\mathbf{7 5}$, wherein the enol ether $\mathbf{7 6}$ was easily produced by acetic anhydride treatment. The L-mannoconfigured 77 was acquired after hydrogenation. Subsequent deacetylation and acetal hydrolysis produced L-mannose (78). On reduction with $\mathrm{NaBH}_{4}, 75$ was alternatively transformed into compound $\mathbf{7 9}$, which furnished L-talose (80) on acid hydrolysis of the diacetonide. Compound 79 is also a suitable precursor for the L-talose building block $\mathbf{8 2}$ designed for the synthesis of capuramycin. The required transformations, which included 3-O-methylation, regioselective isopropylidene deprotection, and silylation, were all carried out in high yields. The 3-hydroxyl of the $\mathrm{L}$-talose derivative $\mathbf{7 9}$ further allows conversion back to the $\mathrm{L}-i d o$ form. Hence, through the tosylate 83, the $\mathrm{L}-i d o$ 3-fluoro and 3-azido compounds 84 and 85 were, respectively, formed via $\mathrm{S}_{\mathrm{N}} 2$ substitution under the agency of $\mathrm{NaN}_{3}$ or diethylaminosulphur trifluoride (DAST). To access L-altrose, the C-3 and C-4 positions in $\mathbf{7 9}$ need to be inverted. Exposure to DAST supplied the enol ether $\mathbf{8 6}$ and the ensuing hydroboration gave the $\mathrm{L}$-altro-configured $\mathbf{8 7}$. Cleavage of the isopropylidene acetals led to L-altrose (88).

The L-idose derivative $\mathbf{6 4}$ was also shown to directly form 1,6-anhydro-L-idose (89) under reflux conditions with an acid (Scheme 8). This fruitful transformation has enabled a separate epimerisation route towards the preparation of $\mathrm{L}$-altro, $\mathrm{L}-$ allo, and L-gulo derivatives from 1,6-anhydro-L-idose. ${ }^{45 d, e, 47}$ The rigid structure of the 1,6-anhydro ring generally forces the L-hexose to assume an atypical conformation that profoundly affects the reactivity of the substituent oxygens. This, together with the decrease in the hydroxyl groups that need to be protected, made 1,6-anhydrosugars as valuable building blocks in carbohydrate synthesis. ${ }^{48}$ Per-trimethylsilylation and reductive 3-O-benzylation of 89 produced the diol $\mathbf{9 0}$. Alternatively, $\mathbf{9 0}$ was also obtained from the mesylate 91, itself likewise derived from starting material $58 .^{49}$ Here, treatment with potassium tertbutoxide cleaves the benzoyl group at O-6 and the alkoxide formed attacks $\mathrm{C}-5$ on the backside to afford the $\mathrm{L}-\mathrm{i} d o$

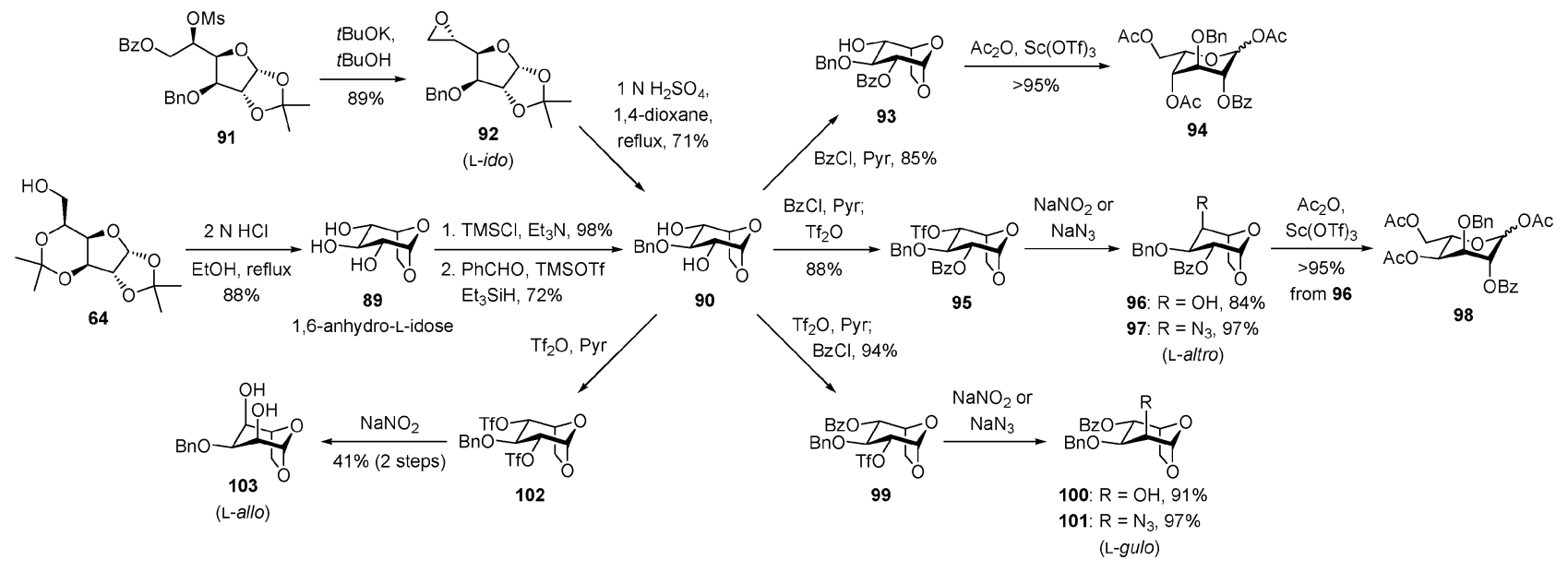

Scheme 8 Synthesis of L-hexoses through 1,6-anhydrohexopyranoses. 
epoxide 92. Reflux together with $\mathrm{H}_{2} \mathrm{SO}_{4}$ in 1,4-dioxane supplied the target compound $\mathbf{9 0}$. The control in reactivity was demonstrated by regioselective 2-O-benzoylation acquiring the 4-alcohol 93 in 85\% yield. An efficient method developed by our group opens the anhydro-ring using metal triflate-mediated acetolysis. ${ }^{50}$ Thus, the triacetate 94 was procured under $\mathrm{Sc}(\mathrm{OTf})_{3}$ catalysis in excellent yield. In a separate report, Wong et al. showed that the same ring opening can be facilitated by a nucleophilic sulphur reagent such as trimethyl(methylthio)silane in the presence of trimethylsilyl triflate (TMSOTf). ${ }^{51}$ Taking the differences in reactivity between hydroxyl groups even further, consecutive one-pot benzoylation and triflation supplied the product 95, which was treated with either $\mathrm{NaNO}_{2}$ or $\mathrm{NaN}_{3}$ to form the alcohol 96 or the azido 97 in the L-altro-configuration. Again, acetolysis facilitated by $\mathrm{Sc}(\mathrm{OTf})_{3}$ efficiently led to the L-altrose triacetate compound 98. Knowing that L-gulose is a C-2 epimer of L-idose, we followed the reverse order of reagent addition to 90 in one pot to get the 2-triflate 99 , which was treated similarly to 95 to form the L-gulo derivatives $\mathbf{1 0 0}$ and 101. A double triflation of $\mathbf{9 0}$ equally granted access to the L-allo diol 103.

\section{Head-to-tail inversions}

Four D-hexoses, namely, D-glucose, D-galactose, D-gulose, and D-allose, have an $R$-configured C-2. Consequently, an exchange of oxidation states between $\mathrm{C}-1$ and C- 6 in these sugars should make $\mathrm{C}-2$ become the new C-5 in $S$-configuration. Under this premise, reduction of the aldehyde function at C-1 to a primary alcohol and oxidation of
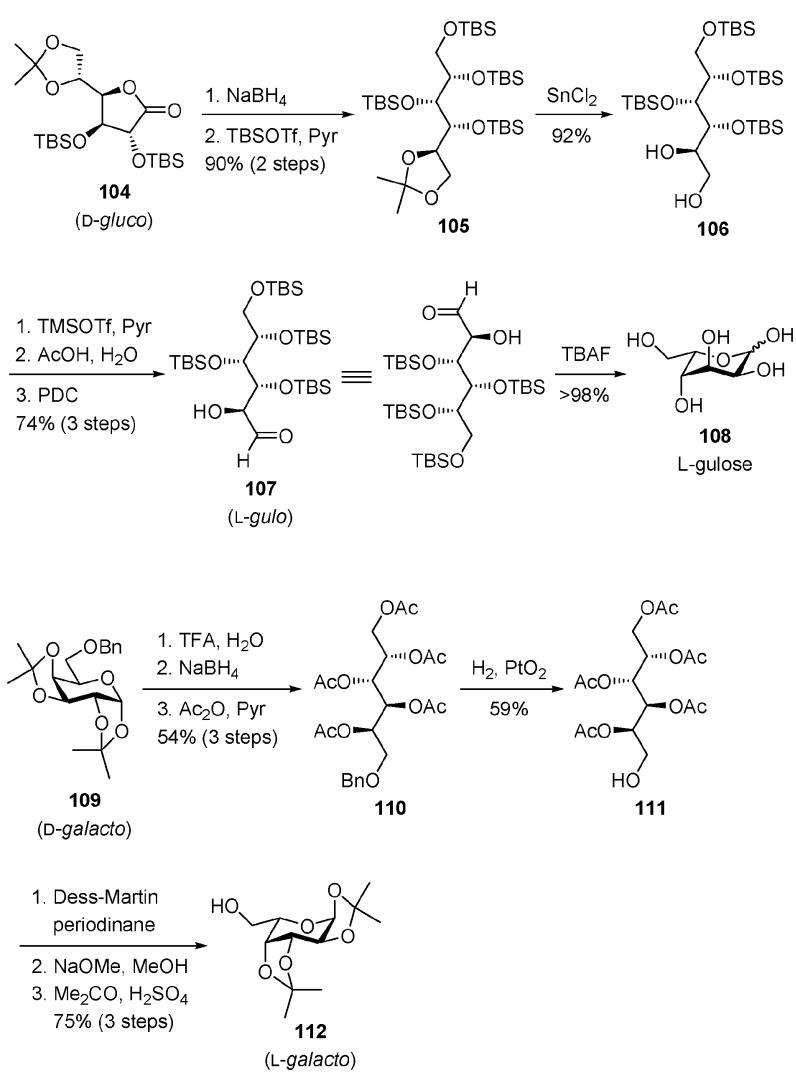

Scheme 9 Examples of C-1-to-C-6 inversion.
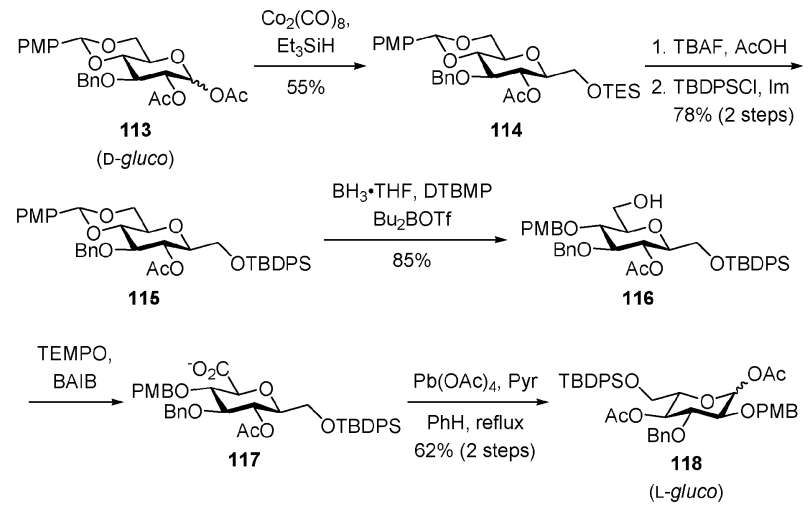

Scheme 10 C-1-to-C-5 inversion involving a $\beta$-C-glucoside.

the C-6 alcohol to an aldehyde in D-glucose, D-galactose, D-gulose, and $\mathrm{D}$-allose would generate L-gulose, L-galactose, L-glucose, and L-allose, respectively. Scheme 9 illustrates two examples applying this notion.

The D-glucono-1,4-lactone $\mathbf{1 0 4}$ was first reduced using $\mathrm{NaBH}_{4}$ and the generated diol was protected with TBS to afford the tetrasilylated 105. $^{52}$ Chemoselective cleavage of the isopropylidene group was implemented using $\mathrm{SnCl}_{2}$ leading to the diol 106, which was re-protected with trimethylsilyl (TMS) groups. After cleavage of the primary TMS ether under mildly acidic conditions, the exposed alcohol was oxidised to furnish the aldehyde $\mathbf{1 0 7}$ carrying the L-gulo configuration. L-Gulose (108) was obtained after complete removal of all silyl groups. L-Xylose was also obtained from compound 106 upon treatment with Dess-Martin periodinane followed by full desilylation.

To access the L-galacto derivative $112,{ }^{53}$ the diacetonide in the 6-O-benzylated D-galactose 109 was first cleaved to expose the aldehyde, which was reduced with $\mathrm{NaBH}_{4}$. The pentaacetate 110, acquired after per-acetylation, was subjected to hydrogenolysis to afford the alcohol 111. Oxidation of the primary alcohol to the aldehyde, followed by deacetylation and diisopropylidene installation supplied the target L-hexose $\mathbf{1 1 2}$.

The presence of latent symmetry at C-2, C-3, and C-4 positions in D-glucose could also be exploited in a strategy that follows the switching of the C-1 and C-5 positions (Scheme 10). Thus, $\mathrm{Li}$ and co-workers conceived an approach to L-glucose involving the $\beta$-C-glycoside $\mathbf{1 1 4}$ prepared from the $\mathrm{D}$-glucosyl acetate 113 using $\mathrm{Co}_{2}(\mathrm{CO})_{8}$-catalysed silyloxymethylation. ${ }^{54}$ After installation of the more stable tert-butyldiphenylsilyl (TBDPS) in place of the triethylsilyl (TES) group, the regioselective 6-O ring opening of the $p$-methoxybenzylidene acetal led to the 6-alcohol 116. Subsequent treatment with TEMPO in the presence of [bis(acetoxy)iodo]benzene (BAIB) fashioned the carboxylate 117, which is amenable to oxidative decarboxylation. Accordingly, reflux with lead tetraacetate in a benzenepyridine mixed solvent completed the C-1-to-C-5 switch and provided the L-glucosyl acetate 118. The resultant compound holds orthogonal protecting groups that are very useful in sugar assembly.

Another approach that interchanges the C- 1 and $\mathrm{C}-5$ positions through a glycal intermediate is described in Section 5. 


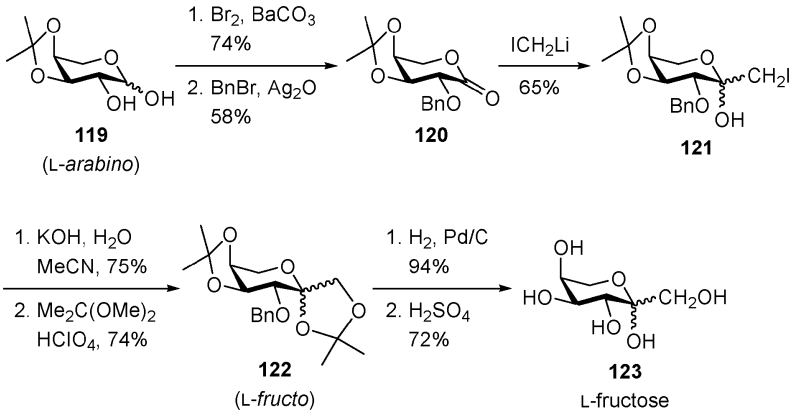

Scheme 11 Preparation of $\mathrm{L}$-fructose from L-arabinose.

\section{Through pentoses}

The homologation of pentoses to hexoses is traditionally carried out using the Kiliani-Fischer synthesis via a cyanohydrin, albeit with poor stereoselectivity. Conversely, there are several recent strategies that follow the pentose elongation process precisely targeting L-hexoses with good to exceptional selectivity. Some prominent examples are herein described.

The preparation of $\mathrm{L}$-fructose by iodomethylation of $\mathrm{L}$-arabino1,5-lactone was described by Bessières and Morin (Scheme 11). ${ }^{55}$ Lactone 120 was first prepared from the hemiacetal 119. The iodide 121, generated upon treatment with $\mathrm{ICH}_{2} \mathrm{Li}$, was converted to the primary alcohol by $\mathrm{S}_{\mathrm{N}} 2$ substitution. The ensuing diol was protected with an acetonide to get compound 122, which already holds an L-fructo configuration. Subsequent debenzylation and acid hydrolysis supplied the desired L-fructose (123).

L-Iduronate building blocks carrying orthogonal protecting groups were fashioned by Seeberger et al. from D-xylose (Scheme 12) ${ }^{56}$ In contrast to the typical cyanohydrin formation, which occurs at $\mathrm{C}-1$ of the pentose, the cyanide group was added, in this case, to the aldehyde group that was formed at the C-5 position. Following tritylation and benzylation of the diol 124, the thioacetal 126 was synthesized using $\mathrm{ZnBr}_{2}$ and a
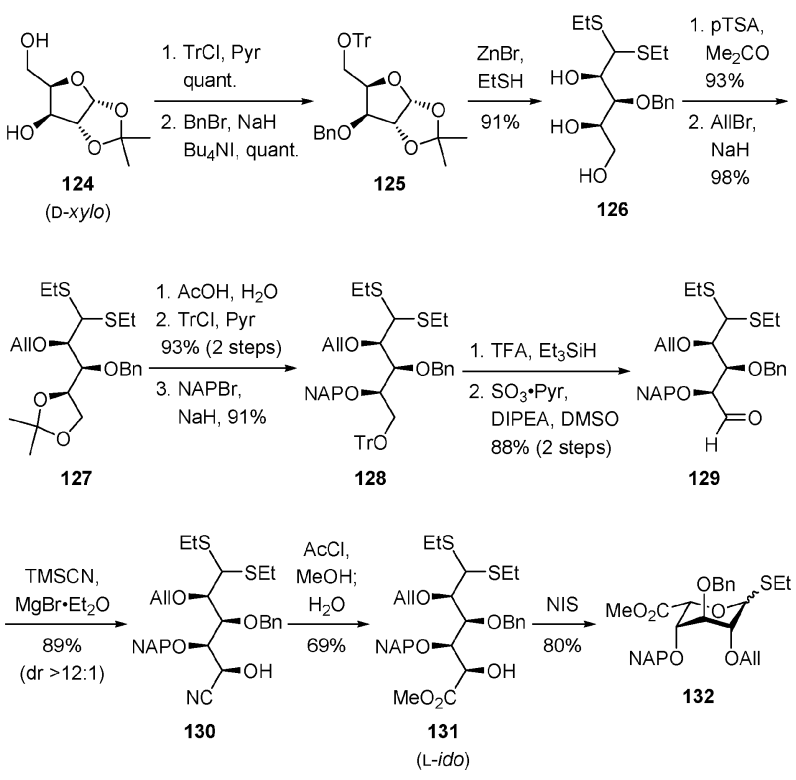

Scheme 12 Synthesis of L-iduronate from D-xylose.

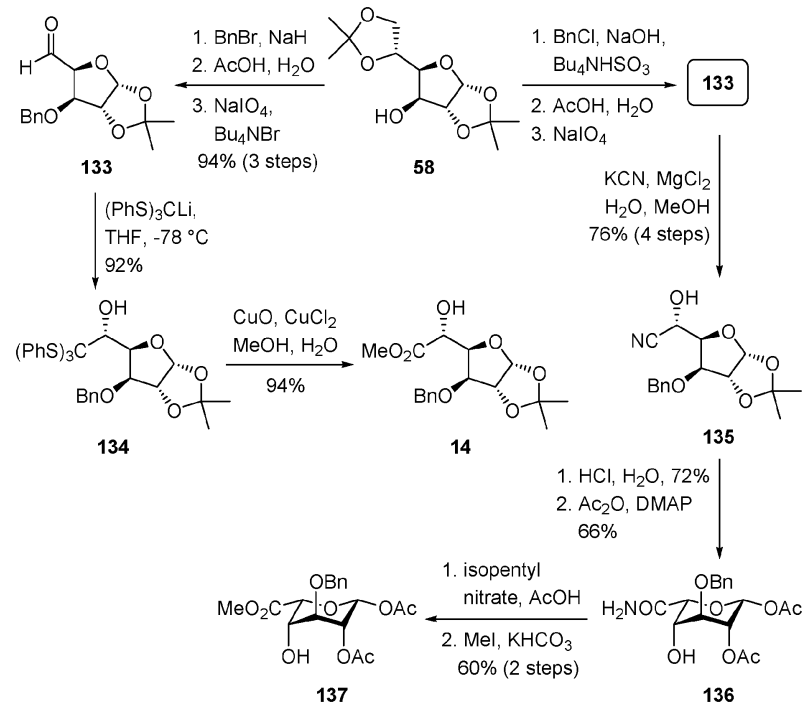

Scheme 13 Synthesis of L-iduronate through D-xylo dialdose.

large excess of ethanethiol. Various manipulations of this triol were then carried out to afford the orthogonally protected $\mathbf{1 2 8}$ (NAP: 2-naphthylmethyl, All: allyl). The trityl (Tr) group in compound 128 was next removed and the resulting alcohol was subjected to Parikh-Doering oxidation to access the aldehyde 129. Using $\mathrm{MgBr} \cdot \mathrm{Et}_{2} \mathrm{O}$ as a chelate activator, the cyanide addition occurred in excellent yield and diastereoselectivity for the $\mathrm{L}-i d o-$ configured cyanohydrin 130. Transformations under successive methanolic $\mathrm{HCl}$ (Pinner reaction) and hydrolysis provided the methyl ester 131, which cyclised to the pyranose form 132 after $N$-iodosuccinimide (NIS) treatment.

An aldehyde function at the C-5 position of a D-xylo compound could also be accessed from diacetone D-glucose (58) (Scheme 13). Accordingly, 3-O-benzylation, 5,6-O-isopropylidene cleavage, and periodate oxidation handily gave the $\mathrm{D}-x y l o$ dialdose 133. In a procedure developed by Bonnaffé, ${ }^{57}$ the steric bulk of the carboxylic acid equivalent tris-(phenylthio)methyllithium was instrumental in favouring the $\mathrm{L}-i d o$ configuration and providing compound $\mathbf{1 3 4}$ in complete stereoselectivity. The orthothioesters were effectively transformed to the methyl ester 14 in the presence of $\mathrm{CuO}$ and $\mathrm{CuCl}_{2}$. Gardiner's group, ${ }^{58}$ on the other hand, performed cyanide addition with $\mathrm{MgCl}_{2}$ to shift the stereoselectivity towards L-idose (about 90\% de). The compound formed after acid-mediated uronamide formation and acetal hydrolysis was diacetylated to obtain the pyranose 136. Further transformation to the carboxylic acid and esterification led to the L-iduronate 137.

\section{Through unsaturated pyranosides}

Approaches towards L-hexoses were also developed using intermediates with unsaturated pyranosides directly prepared from D-hexoses. These strategies, mainly introduced by Wei et al., ${ }^{28 b, 59}$ involve stereoselective epoxidation of 4-deoxypentenosides and glycals followed by nucleophilic attack in syn or anti manner. Moreover, D-glycals require a switch between C-1 and C-5 after nucleophilic addition in order to arrive at the proper $\mathrm{L}$-configuration. The route 


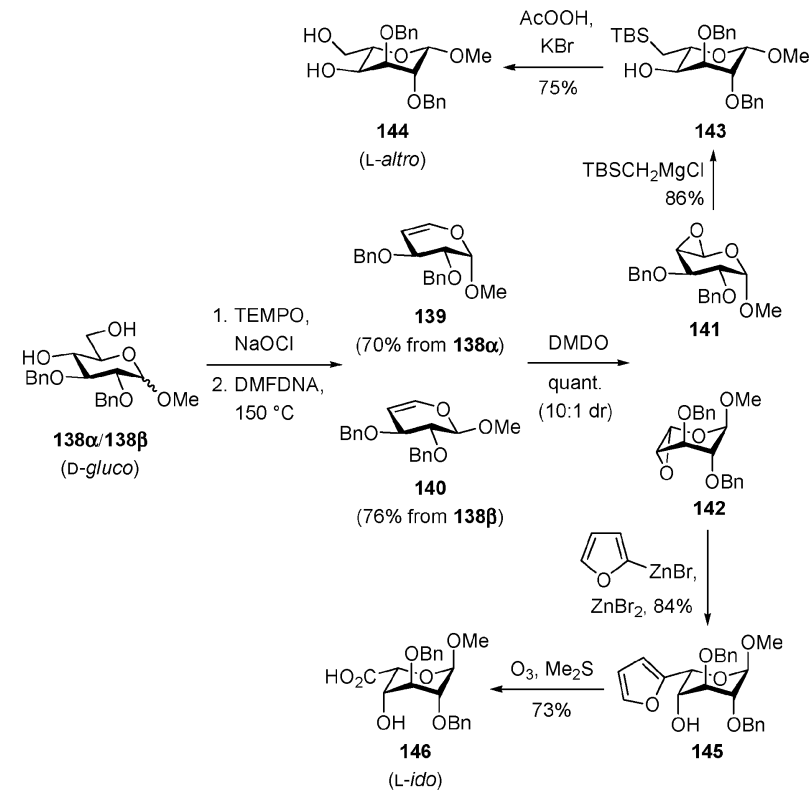

Scheme 14 Preparation of L-hexoses through a 4-deoxypentenoside intermediate.

leading to the L-sugar also allows for the introduction of unnatural C-5 substituents simply by the choice of nucleophile.

Scheme 14 describes the alternate transformations of 4-deoxypentenosides used for the preparation of L-hexoses. ${ }^{59 a, c}$ The D-glucosyl diol 138 is amenable to TEMPO oxidation towards the carboxylate, which was then refluxed with dimethylformamide dineopentyl acetal (DMFDNA) to enable decarboxylative elimination generating the pentenosides 139 and 140. The separate exposure of these pentenosides to dimethyldioxirane (DMDO) furnished the epoxides 141 and 142. As exhibited in these examples, the steric environment, particularly the substituent at C-1, has profound influence on the orientation of the formed epoxide. An $\mathrm{S}_{\mathrm{N}} 2$-type anti-addition of a silylated nucleophile at the less hindered C-5 position in the epoxide 141 led to the L-configured 4-alcohol 143. Tamao-Fleming oxidation delivered the L-altrose derivative 144. Conversely, a C-5 syn-addition of a nucleophile is required for the epoxide $\mathbf{1 4 2}$ to guarantee the L-configuration. In this case, the addition of 2 -furylzinc bromide, prepared by addition of zinc bromide to an $n$ BuLi-treated furan, proceeded with high $s y n$-stereoselectivity to obtain compound 145. The L-iduronic acid derivative 146 was obtained after ozonolysis.

Glycals have been effectively utilized as building blocks in oligosaccharide assembly. ${ }^{60}$ The facile manipulation of the double bond function and ready availability of C-5 decarboxylation methods also provide access to L-hexoses that are difficult to obtain using 4-deoxypentenosides. For instance, the D-glucal 148, generated from the pentaacetate 147 in 5 steps, was converted to the L-galactose derivative 155 (Scheme 15). ${ }^{28 b, 59 b}$ The route towards L-glucose is also evident using this strategy. Accordingly, epoxidation of 148 fashioned compound 149, with the orientation of oxirane group guided by the steric bulk of other ring substituents. The anti-attack by a silyl methyl nucleophile followed by Tamao-Kumada oxidation produced the diol 150. After benzylation of the exposed primary alcohol, a
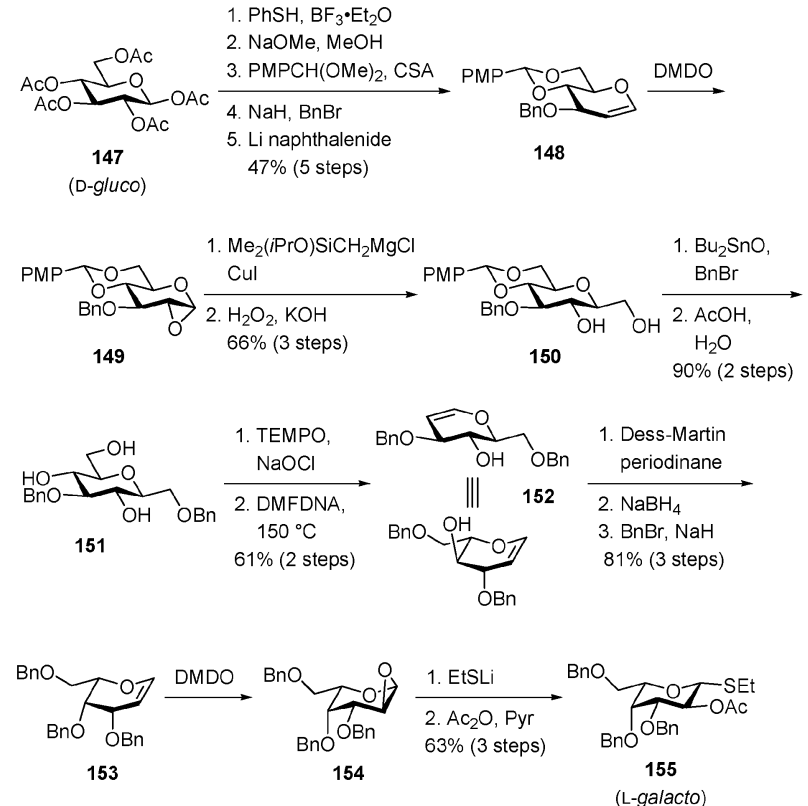

Scheme 15 Synthesis of L-galactose derivative through a D-glucal intermediate.

similar oxidation-decarboxylative elimination sequence switched the C-1 and C-5 positions effectively generating the L-glycal 152. Successive C-4 epimerisation, benzylation, epoxidation, thioethyl addition, and acetylation effectively delivered the target thiogalactoside 155.

\section{Hydroxylation of 6-deoxy-L-hexoses}

As already stated, two 6-deoxy-L-hexoses (i.e., L-rhamnose and L-fucose) are more accessible than the rest of the L-hexoses. Such availability provides a convenient opportunity for the direct synthesis of their rare fully hydroxylated counterparts. However, activation of the inherently unreactive primary $\mathrm{C}-\mathrm{H}$ bond in the presence of multiple functional groups that are found in carbohydrates is a challenge. Recently, Simmons and Hartwig disclosed an approach in site-selective functionalisation of primary methyl groups that requires an iridium catalyst and a free $\gamma$-hydroxyl as a directing group. ${ }^{61}$ Shortly after, the group led by Bols applied this method for generating the respective derivatives of $\mathrm{L}$-mannose and L-galactose from L-rhamnose and L-fucose, respectively (Scheme 16). ${ }^{62}$

To primarily provide for the specific $\gamma$-hydroxyl needed by this approach, the methyl L-rhamnoside 156 and methyl L-fucoside $\mathbf{1 5 7}$ were first prepared from the free sugars. The isopropylidene and butane-2,3-diacetal protecting groups were particularly chosen to evaluate the regioselectivity of $\mathrm{C}-\mathrm{H}$ bond activation. Treatment of these 4-alcohols with diethylsilane $\left(\mathrm{Et}_{2} \mathrm{SiH}_{2}\right)$ and $0.5 \mathrm{~mol} \%$ [Ir(cod)OMe $]_{2}$ (cod: 1,5-cyclooctadiene) at room temperature led to the (hydrido)silyl ethers 158 and 159. After removal of the solvent and excess silane reagent in vacuo, more iridium catalyst (up to $2 \mathrm{~mol} \%$ ), the ligand 3,4,7,8tetramethyl-1,10-phenanthroline (3,4,7,8-Me $\left.\mathrm{Me}_{4} \mathrm{Phen}\right)$, and norbornene were added together with the solvent. The iridium-catalysed $\mathrm{C}-\mathrm{H}$ activation occurred at high temperature $\left(120^{\circ} \mathrm{C}\right)$, enabling the formation of the cyclic silyl ethers 160 and 161. Subsequent 

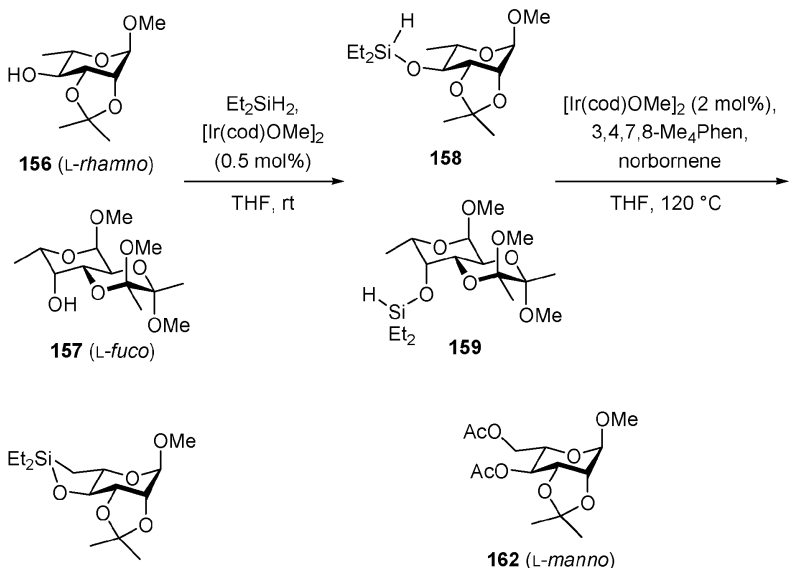

160

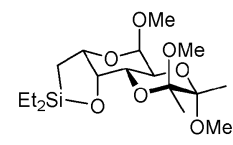

161
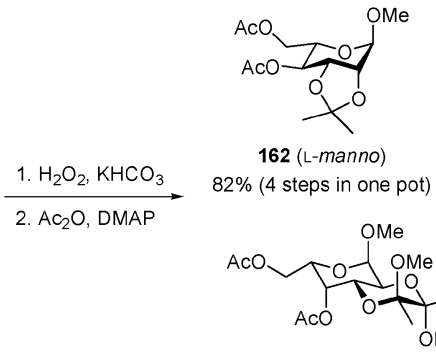

$82 \%$ (4 steps in one pot)

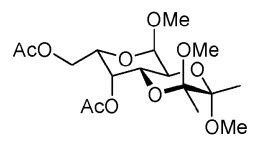

163 (L-galacto)

$67 \%$ (4 steps in one pot)

Scheme 16 Synthesis of L-mannose and L-galactose from L-rhamnose and $\mathrm{L}$-fucose, respectively, by primary $\mathrm{C}-\mathrm{H}$ bond activation.

Tamao-Fleming oxidation resulted in the L-mannosyl and L-galactosyl 4,6-diols, which were further acetylated to afford the fully protected derivatives 162 and 163. The whole four-step procedure was achieved in one pot and in $82 \%$ and $67 \%$ overall yields for the synthesised L-manno and L-galacto compounds. The other methyl groups were left untouched during the process.

\section{Some applications in sugar assembly}

As a testament to the simplicity and convenience offered by the transformation routes, the more common pentoses and

hexoses remain the principal source of L-hexose building blocks needed for the assembly of oligosaccharides and other complex sugar-containing molecules. De novo strategies, with their wealth of fascinating chemistry, found worth primarily in accessing rare sugar and sugar-like backbones within natural product structures. ${ }^{29}$ The furfural-based method by O'Doherty et $a .^{32 a, b}$ appears to be the only de novo approach to L-hexoses that has so far demonstrated extensions toward the preparation of oligosaccharides. ${ }^{63}$ Typical at the course of the L-hexose preparation, suitable protecting groups are installed to accommodate subsequent manipulation and coupling. Hereafter are some examples of sugar assembly and synthesis that involve L-hexoses.

The biological activities of heparin and heparan sulphate are subject of keen investigations and the chemical synthesis of these sugars received considerable attention. ${ }^{36}$ To supply well-defined oligosaccharides for evaluation, we have carried out the synthesis of several heparin- and heparan sulphate-based analogues that hold regular ${ }^{49 a, c, 64}$ and irregular $^{65}$ repeating disaccharide units. Key to these preparations is the 1,6-anhydro$\beta$-L-idopyranosyl 4-alcohol 93. Condensation of this acceptor with the D-glucosaminyl donor 164 led to the disaccharide 165 in 84\% yield and exclusive $\alpha$-stereoselectivity (Scheme 17). The anhydro ring of the L-idose moiety could be easily manipulated through acetolysis, anomeric deacetylation, and trichloroacetimidation to generate the disaccharide donor 167 . We also demonstrated that, following acetolysis of the anhydro ring, treatment with trimethyl(4-methylphenylthio)silane and $\mathrm{ZnI}_{2}$ could yield the corresponding thioglycoside donor without affecting other protecting groups. ${ }^{64}$ The trichloroacetimidate 167 was then coupled to the acceptor 166, which was acquired from 165 by exposure to DDQ, to afford the tetrasaccharide 168 in excellent yield and stereoselectivity. In this case, the 2-O-benzoyl group in the L-idose unit of the donor provided neighbouring group assistance to promote 1,2-trans glycosylation. Further deprotection
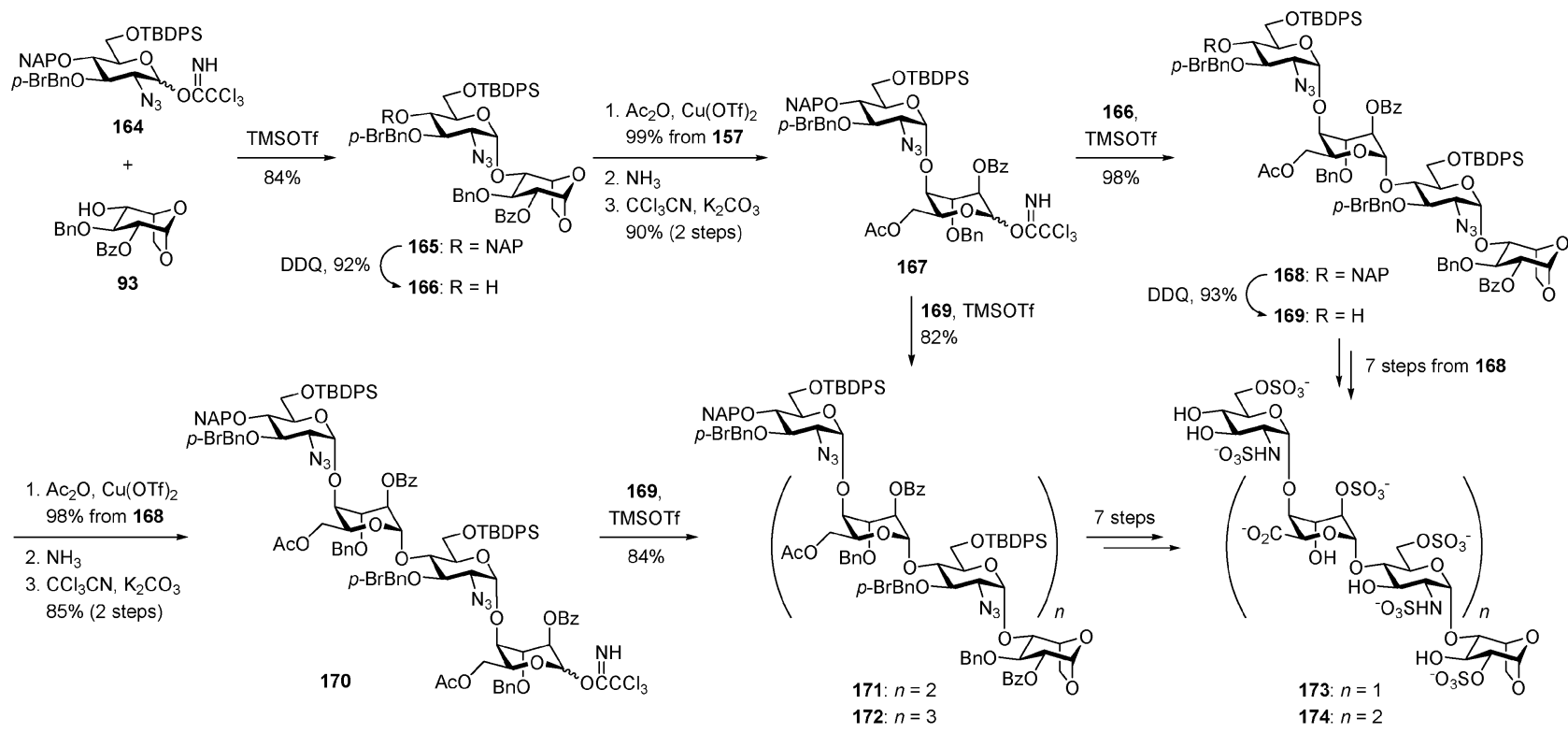

Scheme 17 Preparation of heparin analogues. 

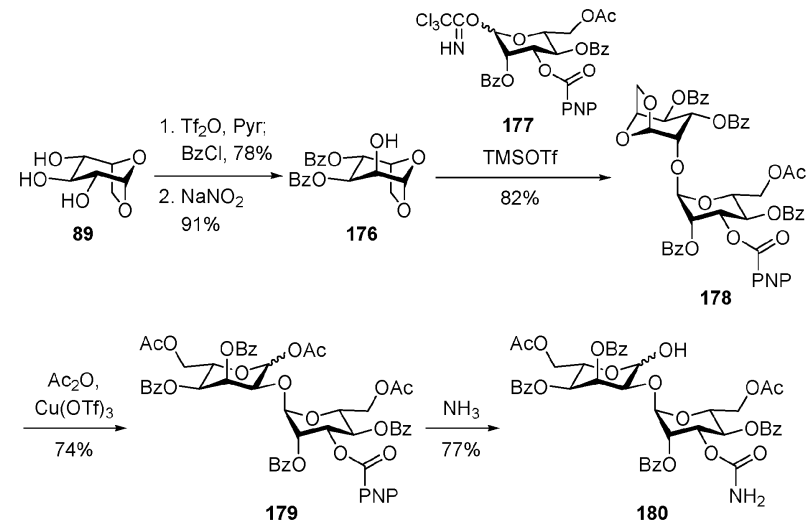

Scheme 18 Preparation of the disaccharide unit of bleomycins.

of the NAP group to form the tetrasaccharide acceptor 169, manipulation of the anhydroidose to form the tetrasaccharide donor 170, and $[2+4]$ - and [4+4]-glycosylations supplied the fully protected hexasaccharide 171 and octasaccharide 172. A series of seven functional group transformation steps eventually furnished the heparin-like tetra-, hexa- and octasaccharides 173-175. Here, the benzoyl, acetyl, and benzyl groups confer protections to the L-idose hydroxyls that were later sulphonated, oxidised, and left unprotected, respectively.

The disaccharide moiety possessing the backbone of the sugar unit in bleomycins was prepared using the 1,6-anhydro-Lgulose derivative 176 (Scheme 18). ${ }^{45 e}$ This compound was prepared using standard procedures from 1,6-anhydro-L-idose (89). Coupling of $\mathbf{1 7 6}$ with the D-mannosyl trichloroacetimidate 177 gave the disaccharide 178 in $82 \%$ yield. Treatment with $\mathrm{Cu}(\mathrm{OTf})_{2}$ and $\mathrm{Ac}_{2} \mathrm{O}$ produced the triacetate 179, which was subjected to ammonialysis to acquire the sugar unit 180 that can be used in bleomycin preparation.

Alginate oligosaccharides with L-guluronic acid repeating units have also been prepared. ${ }^{66}$ In our case, ${ }^{66 b}$ the monosaccharide building blocks 181 and 182, which were both acquired in 4 steps from 1,6-anhydro-L-gulose, were coupled under the agency of TMSOTf to procure the desired $\alpha$-disaccharide 183 together with its $\beta$-isomer in $70 \%$ and $17 \%$ yields, respectively (Scheme 19). Cycles of acetolysis, anomeric deacetylation, trichloroacetimidate formation, and glycosylation of the acceptor 182 ultimately delivered the hemiacetals 186-188. Highly stereoselective $\alpha$-allylations were successfully implemented via Williamson etherification with allyl bromide and potassium tert-butoxide as reagents. The so-formed compounds 189-191 were converted to the alginate di-, tri-, and tetrasaccharides 192-194 by Zemplén deacetylation, TEMPO oxidation, and hydrogenolysis.

With the hope that the mirror image counterparts of natural sugar constructs may provide important biological activities, Wei and co-workers synthesised the trisaccharide mirror image of the H-type II blood group determinant (Scheme 20). ${ }^{28 b}$ The L-glucal 152 and the L-galactoside donor 155 were condensed in the presence of MeOTf and 2,6-di-tert-butyl-4-methylpyridine (DTBMP) to afford compound 195 in $73 \%$ yield. $N$-Sulfonylaziridine formation (IDPC: iodonium di-sym-collidine perchlorate) at the $\alpha$-face of the L-glucal unit followed by displacement with

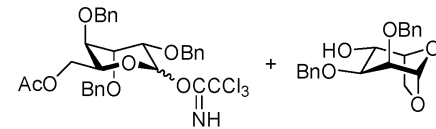

181

181
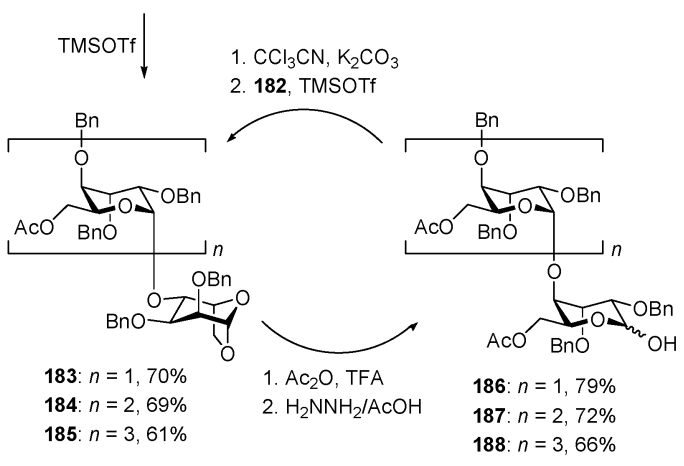

AllBr, tBuOK

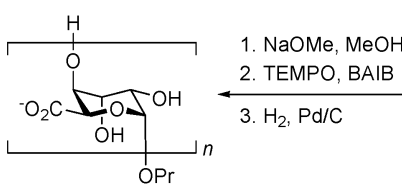

192: $n=2,85 \%$

193: $n=3,65 \%$

194: $n=4,47 \%$

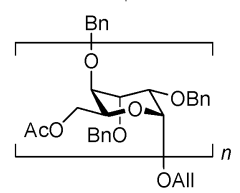

189: $n=2,79 \%$

190: $n=3,74 \%$

191: $n=4,71 \%$
Scheme 19 Preparation of alginate oligosaccharides.

NaOMe furnished the compound which produced the $\mathrm{N}$-acetyl lactosamine derivative 196 after acetylation. Further treatment
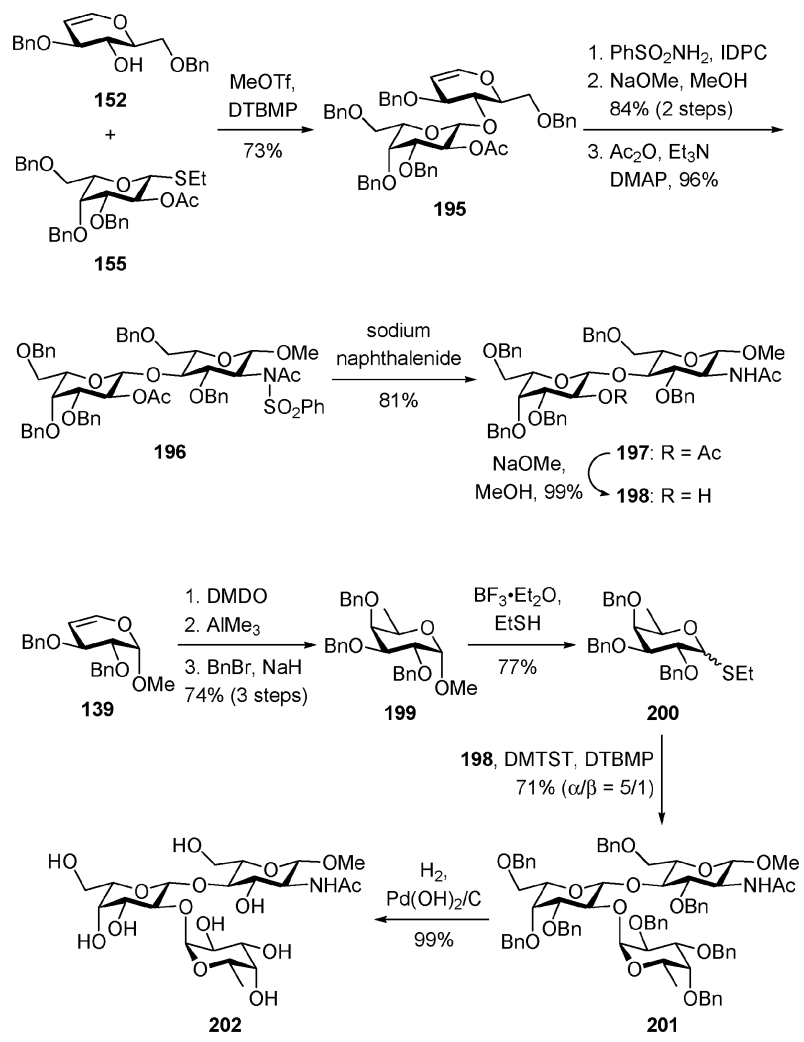

Scheme 20 Preparation of the H-type II blood group determinant mirror image trisaccharide. 
with sodium naphthalenide provided the acetamide 197, which was deacetylated to afford the $2^{\prime}$-alcohol 198. Meanwhile, the methyl D-fucoside 199 was prepared from the 4-deoxypentenoside 139. Herein, the addition of the methyl group at the C-5 position occurred in a syn manner similar to that with 2-furylzinc bromide. Compound 199 was then transformed into the thioglycoside 200 using $\mathrm{BF}_{3} \cdot \mathrm{Et}_{2} \mathrm{O}$ and $\mathrm{EtSH}$. The subsequent glycosylation of the acceptor 198 upon activation of 200 with dimethylsulfonium triflate (DMTST) supplied the fully protected disaccharide 201 . Global hydrogenolysis fashioned the target trisaccharide 202 .

\section{Conclusions}

As the vital roles played by sugars in biological systems continue to be unravelled, the demand for chemically pure and defined carbohydrate constructs needed to understand structure-function relationships will remain high. The versatile, simple, and often cost-effective protocols in accessing L-hexose derivatives described here, as well as future improvements thereof, should provide suitable building blocks for the assembly of sugars and other natural products. Current approaches to L-hexoses from abundant pentoses and hexoses also benefit heavily from the rapid advances in mainstream carbohydrate chemistry, allowing for convenient integration in oligosaccharide preparation. The unusual sugar skeletons found in natural products, on the other hand, offer enduring challenges that are bound to keep carbohydrate chemists occupied in the years to come. These endeavours should further advance glycobiology as a whole and hopefully lead to novel and interesting pharmaceuticals of tomorrow.

\section{References}

1 R. A. Dwek, Chem. Rev., 1996, 96, 683.

2 R. Apweiler, H. Hermjakob and N. Sharon, Biochim. Biophys. Acta, 1999, 1473, 4.

3 G. Walsh and R. Jefferis, Nat. Biotechnol., 2006, 24, 1241.

4 M. L. DeMarco, Biochemistry, 2012, 51, 5725.

5 A. C. Weymouth-Wilson, Nat. Prod. Rep., 1997, 14, 99.

6 R. M. Schmaltz, S. R. Hanson and C.-H. Wong, Chem. Rev., 2011, 111, 4259.

7 Comprehensive Glycoscience: From Chemistry to Systems Biology, ed. J. P. Kamerling, Elsevier, Amsterdam, 2007.

8 T. J. Boltje, T. Buskas and G.-J. Boons, Nat. Chem., 2009, 1, 611.

9 (a) R. I. Hollingsworth and G. Wang, Chem. Rev., 2000, 100, 4267; (b) M. Diéguez, O. Pàmies and C. Claver, Chem. Rev., 2004, 104, 3189.

10 (a) R. Sasisekharan, R. Raman and V. Prabhakar, Annu. Rev. Biomed. Eng., 2006, 8, 181; (b) N. S. Gandhi and R. L. Mancera, Chem. Biol. Drug Des., 2008, 72, 455.

11 K. I. Draget and C. Taylor, Food Hydrocolloids, 2011, 25, 251.

12 A. St. Swierzko, A. S. Shashkov, S. N. Senchenkova, F. V. Toukach, A. Ziolkowski, M. Cedzynski, N. A. Paramonov, W. Kaca and Y. A. Knirel, FEBS Lett., 1996, 398, 297.

13 K. Hermansson, L. Kenne, B. Lindberg, B. Arie, R. G. Brown and J. E. Stewart, Carbohydr. Res., 1990, 208, 145.

14 R. J. Stack, FEMS Microbiol. Lett., 1987, 48, 83.

15 B. L. Ridley, M. A. O'Neill and D. Mohnen, Phytochemistry, 2001, 57, 929.

16 M. Yamazaki, L. Thorne, M. Mikolajczak, R. W. Armentrout and T. J. Pollock, J. Bacteriol., 1996, 178, 2676.

17 J. Chen and J. Stubbe, Nat. Rev. Cancer, 2005, 5, 102.

18 J. Asensio, A. Bastida and J. Jiménez-Barbero, Top. Curr. Chem., 2008, 273, 117.

19 T. Ogita, N. Otake, Y. Miyazaki, H. Yonehara, R. D. Macfarlane and C. J. McNeal, Tetrahedron Lett., 1980, 21, 3203.
20 H. Seto, N. Otake, S. Sato, H. Yamaguchi, K. Takada, M. Itoh, H. S. M. Lu and J. Clardy, Tetrahedron Lett., 1988, 29, 2343.

21 P. T. Daniel, U. Koert and J. Schuppan, Angew. Chem., Int. Ed., 2006, 45, 872 .

22 S. J. Williams, R. H. Senaratne, J. D. Mougous, L. W. Riley and C. R. Bertozzi, J. Biol. Chem., 2002, 277, 32606.

23 Y. Uchio, M. Nagasaki, S. Eguchi, A. Matsuo, M. Nakayama and S. Hayashi, Tetrahedron Lett., 1980, 21, 3775.

24 M. Gutiérrez, T. Capson, H. M. Guzmán, E. Quiñoá and R. Riguera, Tetrahedron Lett., 2004, 45, 7833.

25 R. S. Shallenberger, T. E. Acree and C. Y. Lee, Nature, 1969, 221, 555. 26 (a) N. Baggett, A. K. Samra and A. Smithson, Carbohydr. Res., 1983, 124, 63; (b) J. Mandelli, A. Wajner, R. F. Pires, R. Giugliani and J. C. Coelho, Arch. Med. Res., 2002, 33, 20.

27 S. Esaki, A. Ohishi, A. Katsumata, N. Sugiyama and S. Kamiya, Biosci., Biotechnol., Biochem., 1993, 57, 2099.

28 (a) I. A. Kozlov, S. Mao, Y. Xu, X. Huang, L. Lee, P. S. Sears, C. Gao, A. R. Coyle, K. D. Janda and C.-H. Wong, ChemBioChem, 2001, 2, 741; (b) F. P. Boulineau and A. Wei, J. Org. Chem., 2004, 69, 3391.

29 (a) P. Vogel and I. Robina, in Glycoscience: Chemistry and Chemical Biology, ed. B. Fraser-Reid, K. Tatsuta and J. Thiem, Springer-Verlag, Berlin, 2nd edn, 2008, pp. 857-956; (b) D. D'Alonzo, A. Guaragna and G. Palumbo, Curr. Org. Chem., 2009, 13, 71.

30 (a) M. Takeuchi, T. Taniguchi and K. Ogasawara, Chirality, 2000, 12, 338; (b) M. Honzumi, T. Taniguchi and K. Ogasawara, Org. Lett., 2001, 3, 1355.

31 (a) K. S. Kim, B. H. Cho and I. Shin, Bull. Korean Chem. Soc., 2002, 23, 1193; (b) L. Ermolenko and N. A. Sasaki, J. Org. Chem., 2006, 71, 693.

32 (a) J. M. Harris, M. D. Keranen and G. A. O'Doherty, J. Org. Chem., 1999, 64, 2982; (b) J. M. Harris, M. D. Keränen, H. Nguyen, V. G. Young and G. A. O'Doherty, Carbohydr. Res., 2000, 328, 17; (c) M. M. Ahmed and G. A. O'Doherty, J. Org. Chem., 2005, 70, 10576; (d) W. Du and Y. Hu, Carbohydr. Res., 2006, 341, 725.

33 (a) A. B. Northrup and D. W. C. MacMillan, Science, 2004, 305, 1752; (b) J. Mlynarski and B. Gut, Chem. Soc. Rev., 2012, 41, 587.

34 A. Guaragna, D. D'Alonzo, C. Paolella, C. Napolitano and G. Palumbo, J. Org. Chem., 2010, 75, 3558.

35 (a) K. Izumori, J. Biotechnol., 2006, 124, 717; (b) S. M. Dean, W. A. Greenberg and C.-H. Wong, Adv. Synth. Catal., 2007, 349, 1308.

36 S. B. Dulaney and X. Huang, in Advances in Carbohydrate Chemistry and Biochemistry, ed. H. Derek, Elsevier, Amsterdam, 2012, vol. 67, pp. 95-136.

37 (a) H. A. Orgueira, A. Bartolozzi, P. Schell, R. E. J. N. Litjens, E. R. Palmacci and P. H. Seeberger, Chem.-Eur. J., 2003, 9, 140; (b) A. Saito, M. Wakao, H. Deguchi, A. Mawatari, M. Sobel and Y. Suda, Tetrahedron, 2010, 66, 3951.

38 H. N. Yu, J.-i. Furukawa, T. Ikeda and C.-H. Wong, Org. Lett., 2004, 6, 723.

39 L. Rochepeau-Jobron and J.-C. Jacquinet, Carbohydr. Res., 1997, 303, 395.

40 (a) T. Oshitari and S. Kobayashi, Tetrahedron Lett., 1995, 36, 1089; (b) T. Oshitari, M. Shibasaki, T. Yoshizawa, M. Tomita, K.-i. Takao and S. Kobayashi, Tetrahedron, 1997, 53, 10993.

41 (a) H. Takahashi, Y. Hitomi, Y. Iwai and S. Ikegami, J. Am. Chem. Soc., 2000, 122, 2995; (b) H. Takahashi, T. Shida, Y. Hitomi, Y. Iwai, N. Miyama, K. Nishiyama, D. Sawada and S. Ikegami, Chem.-Eur. J., 2006, 12, 5868.

42 (a) S. Yan, X. Liang, P. Diao, Y. Yang, J. Zhang, D. Wang and F. Kong, Carbohydr. Res., 2008, 343, 3107; (b) X. Cai, G. Zong, Y. Xu, J. Zhang, X. Liang and D. Wang, Carbohydr. Res., 2010, 345, 1230.

43 H. Wehlan, M. Dauber, M. T. M. Fernaud, J. Schuppan, S. Keiper, R. Mahrwald, M.-E. J. Garcia and U. Koert, Chem.-Eur. J., 2006, 12, 7378.

44 T.-L. Shih and J.-H. Tseng, Tetrahedron Lett., 2004, 45, 1789.

45 (a) S.-C. Hung, R. Puranik and F.-C. Chi, Tetrahedron Lett., 2000, 41, 77; (b) S.-C. Hung, C.-C. Wang and S. R. Thopate, Tetrahedron Lett., 2000, 41, 3119; (c) S.-C. Hung, S. R. Thopate and R. Puranik, Carbohydr. Res., 2001, 331, 369; (d) S. S. Kulkarni, F.-C. Chi and S.-C. Hung, J. Chin. Chem. Soc., 2004, 51, 1193; (e) J.-C. Lee, S.-W. Chang, C.-C. Liao, F.-C. Chi, C.-S. Chen, Y.-S. Wen, C.-C. Wang, S. S. Kulkarni, R. Puranik, Y.-H. Liu and S.-C. Hung, Chem.-Eur. J., 2004, 10, 399; $(f)$ F.-C. Lu, L. S. Lico and S.-C. Hung, ARKIVOC, 2013, (ii), 13.

46 S.-C. Hung and C.-S. Chen, J. Chin. Chem. Soc., 2000, 47, 1257. 
47 (a) S.-C. Hung, S. R. Thopate, F.-C. Chi, S.-W. Chang, J.-C. Lee, C.-C. Wang and Y.-S. Wen, J. Am. Chem. Soc., 2001, 123, 3153; (b) S.-C. Hung, C.-C. Wang, S.-W. Chang and C.-S. Chen, Tetrahedron Lett., 2001, 42, 1321.

48 S. S. Kulkarni, J.-C. Lee and S.-C. Hung, Curr. Org. Chem., 2004, 8, 475 .

49 (a) J.-C. Lee, X.-A. Lu, S. S. Kulkarni, Y.-S. Wen and S.-C. Hung, J. Am. Chem. Soc., 2004, 126, 476; (b) L.-D. Lu, C.-R. Shie, S. S. Kulkarni, G.-R. Pan, X.-A. Lu and S.-C. Hung, Org. Lett., 2006, 8, 5995; (c) S.-C. Hung, X.-A. Lu, J.-C. Lee, M. D.-T. Chang, S.-l. Fang, T.-c. Fan, M. M. L. Zulueta and Y.-Q. Zhong, Org. Biomol. Chem., 2012, 10, 760.

50 (a) J.-C. Lee, C.-A. Tai and S.-C. Hung, Tetrahedron Lett., 2002, 43, 851; (b) S. S. Kulkarni and S.-C. Hung, Lett. Org. Chem., 2005, 2,670 .

51 P. B. Alper, M. Hendrix, P. Sears and C.-H. Wong, J. Am. Chem. Soc., 1998, 120, 1965.

52 W.-B. Yang, S. S. Patil, C.-H. Tsai, C.-H. Lin and J.-M. Fang, Tetrahedron, 2002, 58, 253.

53 B. Doboszewski and P. Herdewijn, Tetrahedron Lett., 2012, 53, 2253.

54 Y. Li, Z. Yin, B. Wang, X.-B. Meng and Z.-J. Li, Tetrahedron, 2012, 68, 6981.

55 B. Bessières and C. Morin, J. Org. Chem., 2003, 68, 4100.

56 (a) A. Adibekian, P. Bindschädler, M. S. M. Timmer, C. Noti, N. Schützenmeister and P. H. Seeberger, Chem.-Eur. J., 2007, 13, 4510; (b) P. Bindschädler, A. Adibekian, D. Grünstein and P. H. Seeberger, Carbohydr. Res., 2010, 345, 948.

57 (a) A. Lubineau, O. Gavard, J. Alais and D. Bonnaffé, Tetrahedron Lett., 2000, 41, 307; (b) O. Gavard, Y. Hersant, J. Alais, V. Duverger, A. Dilhas, A. Bascou and D. Bonnaffé, Eur. J. Org. Chem., 2003, 2003, 3603.
58 (a) S. U. Hansen, M. Baráth, B. A. B. Salameh, R. G. Pritchard, W. T. Stimpson, J. M. Gardiner and G. C. Jayson, Org. Lett., 2009, 11, 4528; (b) S. U. Hansen, G. J. Miller, M. Baráth, K. R. Broberg, E. Avizienyte, M. Helliwell, J. Raftery, G. C. Jayson and J. M. Gardiner, J. Org. Chem., 2012, 77, 7823.

59 (a) F. P. Boulineau and A. Wei, Org. Lett., 2002, 4, 2281; (b) F. P. Boulineau and A. Wei, Org. Lett., 2004, 6, 119; (c) G. Cheng, R. Fan, J. M. Hernández-Torres, F. P. Boulineau and A. Wei, Org. Lett., 2007, 9, 4849.

60 D. W. Gammon and B. F. Sels, in Handbook of Chemical Glycosylation: Advances in Stereoselectivity and Therapeutic Relevance, ed. A. V. Demchenko, Wiley-VCH, Weinheim, 2008, pp. 416-448.

61 E. M. Simmons and J. F. Hartwig, Nature, 2012, 483, 70.

62 T. G. Frihed, M. Heuckendorff, C. M. Pedersen and M. Bols, Angew. Chem., Int. Ed., 2012, 51, 12285.

63 (a) R. S. Babu, M. Zhou and G. A. O'Doherty, J. Am. Chem. Soc., 2004, 126, 3428; (b) R. S. Babu, S. R. Guppi and G. A. O'Doherty, Org. Lett., 2006, 8, 1605; (c) H. Guo and G. A. O'Doherty, J. Org. Chem., 2008, 73, 5211; (d) R. S. Babu, Q. Chen, S.-W. Kang, M. Zhou and G. A. O'Doherty, J. Am. Chem. Soc., 2012, 134, 11952.

64 M. M. L. Zulueta, S.-Y. Lin, Y.-T. Lin, C.-J. Huang, C.-C. Wang, C.-C. Ku, Z. Shi, C.-L. Chyan, D. Irene, L.-H. Lim, T.-I. Tsai, Y.-P. Hu, S. D. Arco, C.-H. Wong and S.-C. Hung, J. Am. Chem. Soc., 2012, 134, 8988.

65 Y.-P. Hu, S.-Y. Lin, C.-Y. Huang, M. M. L. Zulueta, J.-Y. Liu, W. Chang and S.-C. Hung, Nat. Chem., 2011, 3, 557.

66 (a) J. Dinkelaar, L. J. van den Bos, W. F. J. Hogendorf, G. Lodder, H. S. Overkleeft, J. D. C. Codée and G. A. van der Marel, Chem.-Eur. J., 2008, 14, 9400; (b) F.-C. Chi, S. S. Kulkarni, M. M. L. Zulueta and S.-C. Hung, Chem.-Asian J., 2009, 4, 386. 